\title{
ALMADÉN EN LA EDAD MODERNA. SU TRANSFORMACIÓN URBANÍSTICA DE VILLAZGO A VILLA
}

\author{
Almadén in the Early Modern Period. Its Urban \\ Transformation from Villazgo to Villa
}

María Silvestre Madrid

Universidad de Castilla La Mancha. España maria.silvestre@uclm.es | http://orcid.org/0000-0003-3933-0018

Emiliano Almansa Rodríguez

Universidad de Castilla La Mancha. España

emiliano.almansa@uclm.es | https://orcid.org/0000-0003-3918-5308

Fecha de recepción: 03/05/2021

Fecha de aceptación: 06/10/2021

Acceso anticipado: 08/11/2021

Resumen: La conservación del patrimonio industrial en España ha brillado por su ausencia hasta hace pocos años, cuando se empezó a comprender el valor histórico y cultural de los edificios, máquinas y herramientas, que son la memoria tangible del mundo del trabajo. En el caso de Almadén, al patrimonio minero y metalúrgico, que le ha valido ser inscrito por la UNESCO en junio de 2012 como patrimonio mundial, se une un patrimonio urbanístico que merece sin duda ser conservado para la posteridad. El objetivo de este artículo es precisamente la transformación urbana de Almadén en la segunda mitad del XVIII, cuando pasó de ser un villazgo situado sobre unas labores subterráneas a la villa minera más importante de la España peninsular. Para lograr el objetivo marcado se ha realizado una intensa búsqueda bibliográfica, tanto de los libros y artículos publicados sobre la historia y el patrimonio de Almadén como de los manuscritos, planos y dibujos existentes en los archivos nacionales. Además, se han recorrido en detalle los distintos sitios de la localidad para su descripción y obtención de imágenes. Todo ello nos ha permitido comprender el esfuerzo realizado en plena época de la llustración para convertir Almadén no solo en una mina vital para el desarrollo de la minería de la 
plata en el virreinato de Nueva España sino en una villa moderna en la que los mineros y sus familias tuvieran una vida digna.

Palabras clave: Patrimonio industrial; Historia; Minería; Mercurio; Mineral; Arquitectura.

Abstract: Until very recently, efforts to preserve industrial heritage in Spain have been almost non-existent. Only in the last few years the appreciation of the historical and cultural value of buildings, machines, and tools, which are the tangible memory of the world of labour. In the case of Almadén, the mining and metallurgical heritage, which is a designated UNESCO World Heritage Site since June 2012 , is paired by an urban heritage that undoubtedly deserves to be saved for posterity. The aim of this article is to analyse the changes that Almadén underwent in the second half of the $18^{\text {th }}$ century. During this period, the original hamlet was transformed into the most important mining town in Spain. To this end, the article draws on an exhaustive bibliographic review of works on the history and heritage of Almadén, as well as on research on extant sources from the period, including manuscripts, plans, and drawings, preserved in national archives. Also, different sites in the town have been studied in detail, and images of them have been obtained. The study provides a better appreciation of the effort undertaken in during the Age of Enlightenment to turn Almadén not only into a vital resource for the development of silver mining in the Viceroyalty of New Spain, but also into a modern town where miners and their families could lead a decent life.

Keywords: Industrial heritage; History; Mining; Mercury; Ore; Architecture.

Sumario: 1. Introducción; 2. Desde la época árabe hasta la llustración; 3. La segunda mitad del XVIII; 4. Conclusiones; 5. Referencias bibliográficas; 5.1. Fuentes manuscritas; 5.2. Fuentes impresas.

\section{INTRODUCCIÓN}

El 22 de junio de 1969, el cronista Luis Cavanillas Ávila mandaba una llamada de auxilio porque «desaparecerá la Real Cárcel de Galeras y la Parroquia de San Miguel en Almadén. Aún se está a tiempo para la torre campanario y la iglesia, de gran valor artístico-histórico » ${ }^{1}$. En efecto, sin motivo aparente y puestos de acuerdo el Consejo de Administración de las Minas y el Ayuntamiento de Almadén, se acometió el derribo de la Real Cárcel de Forzados y de la Capilla de San Miguel anexa a la misma, conjunto construido a mediados del siglo XVIII para albergar a los tres centenares de presos que cumplían condena en las labores subterráneas de la mina de Almadén. El citado cronista intentó parar el derribo, para lo que se desplazó a Madrid y mantuvo una entrevista con el director general de Bellas Artes, pero «a golpe de potente excavadora y a base de barrenos la sólida y artística construcción

\footnotetext{
${ }^{1}$ Diario Lanza, Ciudad Real, 22 de junio de 1969, p. 11.
} 
quedó convertida en un solar $\aleph^{2}$. Cuatro años después se construía en ese mismo sitio la Escuela Universitaria de Ingeniería de Minas, como si el edificio carcelario no hubiera podido reconvertirse en universitario o como si este no hubiese sido posible levantarlo en otro lugar de Almadén.

El anterior es un ejemplo más de la despreocupación y falta de estima del patrimonio arquitectónico industrial en España. Numerosos bienes de este tipo ya fuesen edificios aislados o conjuntos industriales, hubieron de sortear hasta épocas relativamente recientes grandes amenazas para no desaparecer. En aquel concepto de desdén institucional, de desinterés académico y de carencia de instrumentos de protección, una parte sustancial del patrimonio industrial y minero español fue eliminado sin oposición legal o social (Benito, 2009, p.198). Conceptos tales como conservación, patrimonio o memoria de la industria eran desconocidos hasta la década de 1970, que fue cuando empezó a valorarse la singularidad del patrimonio industrial ${ }^{3}$.

Por fin, en 1999, la Comisión Europea creó la llamada «Estrategia Territorial Europea», en la que se planteaba "armonizar las exigencias sociales y económicas del desarrollo con las funciones económicas y culturales del territorio y contribuir de esta forma a un desarrollo sostenible y equilibrado" (Comisión Europea, 1999, p. 11). Cuatro años después, en julio de 2003, el Comité Internacional para la Conservación del Patrimonio Industrial (TICCIH) firmó la «Carta de Niznhy Tagil», en la que definía el patrimonio industrial como «los restos de la cultura industrial que poseen un valor histórico, tecnológico, social, arquitectónico o científico» ${ }^{4}$. Poco a poco, la atracción histórica, técnica y simbólica de los monumentos y sitios mineros e industriales suscitaron un creciente interés, pues se trata de un legado de gran impacto visual y escénico asociado a una cultura local propia y ligada estrechamente a la actividad económica tradicional de la zona (Pardo Abad, 2016, p. 332).

Hoy en día, el valor histórico y cultural de los edificios industriales está fuera de toda duda, pues son memoria de un pasado laborioso en un determinado momento histórico. En la actualidad hay un interés creciente de las administraciones, universidades y asociaciones por estudiar, catalogar, inventariar y difundir este patrimonio a través de una nueva disciplina, la Arqueología Industrial (Aguilar Civera, 2004, p. 156). En el año 2000 se aprobó el Plan Nacional de Patrimonio Industrial, lo que permitió en todo el territorio español pasar de la protección legal a la recuperación

2 Ibid.

${ }^{3}$ Hay algunas excepciones al respecto, como la del ingeniero Carlos Mata, quien en 1930 no permitió la demolición de un par de hornos de aludeles de principios del XVIII, sitos en el recinto metalúrgico de la mina de Almadén. En la actualidad son los únicos de este estilo que se conservan en buen estado en todo el mundo.

${ }^{4}$ La «Carta de Nizhny Tagil sobre el patrimonio industrial» se puede consultar en https:// www.icomos.org/18thapril/2006/nizhny-tagil-charter-sp.pdf. Recuperado el 5 de octubre de 2021. 
real, convirtiendo la conservación y reutilización del patrimonio en un importante factor de desarrollo local, tanto cultural como económico 5 . En él tienen cabida todas las manifestaciones arquitectónicas y tecnológicas relacionadas con la producción y distribución, viviendas y equipamientos, e incluso las fuentes documentales. En julio de 2008, el Instituto del Patrimonio Histórico Español (IPHE) promovió la «Carta del Bierzo del Patrimonio Industrial Minero», en la que advertía a la población en general y a las administraciones públicas de la desaparición y abandono de una buena parte de los testimonios de la historia minera e industrial española ${ }^{6}$. Cuando en el 2011 se seleccionaron 100 elementos del Patrimonio Industrial en España, siguiendo criterios vinculados con la antigüedad del bien, con los diversos sectores productivos, con las tipologías arquitectónicas y con la relación de la industria con el territorio, el elemento 39 fue el Paisaje Minero de Almadén 7 . De este modo, quedaba reconocido públicamente el paisaje industrial (minero) de Almadén, su grado de conservación y uso, lo que permite su visita y su conocimiento individualizado ${ }^{8}$. En junio de 2012, la UNESCO otorgaba a Almadén y a Idria o Idrija (Eslovenia) el nombramiento de ambas como Patrimonio Mundial del Mercurio ${ }^{9}$.

Los pueblos mineros son efímeros por lo general, pues dejan de tener razón de ser cuando los yacimientos minerales se agotan. El ejemplo más conocido es el de muchos pueblos abandonados del oeste de los Estados Unidos como consecuencia del cierre de sus minas de oro o plata a finales del XIX, tema recurrente de tantas películas ${ }^{10}$. En España también hay ejemplos parecidos, como la Sierra de Gádor (Alpujarra almeriense), gran productora de plomo en la década de 1820, o Sierra Almagrera, cercana a Cuevas de Almanzora (Almería), de la que se extrajo plomo y

${ }^{5}$ El Plan Nacional de Patrimonio Industrial se puede consultar en https://oibc.oei.es/ uploads/attachments/172/patrimonio_industrial.pdf. Recuperado el 5 de octubre de 2021.

${ }^{6}$ La «Carta del Bierzo del Patrimonio Industrial Minero» se puede consultar en http://www. sedpgym.es/defensa-del-patrimonio/espana/109-carta-de-el-bierzo-del-patrimonio-industrialminero-27-06-2008 Recuperado el 5 de octubre de 2021.

7 Almadén quedaba así unido a otros sitios españoles y europeos en los que la minería ha constituido la base económica de sus territorios durante siglos, pero que las nuevas técnicas de reciclado, la puesta en explotación de yacimientos más rentables o las leyes ambientales más restrictivas han obligado a su abandono.

8 El Parque Minero de Almadén, inaugurado en enero de 2008, muestra al visitante el conjunto de edificios e instalaciones históricos, y también un recorrido guiado por las labores subterráneas de los siglos XVI al XVIII.

${ }^{9}$ Nuevos reconocimientos para el Parque Minero de Almadén en los últimos años han sido: "Anchor Point» de la Ruta Europea del Patrimonio Industrial (ERIH), concedido por el Consejo de Europa; «European Historical Landmarlk 2019», concedido por la European Chemical Society; «European Heritage Label» (EHL), candidatura aprobada por el Consejo de Europa en 2021.

10 Muchos mineros se trasladaron entonces a Alaska, donde se había iniciado una nueva fiebre del oro. 
plata en las décadas de 1840 y 1850 (Pérez de Perceval y López-Morell, 2006, p. 21). Ambas zonas produjeron grandes corrientes migratorias, gentes que se marcharon a otras cuencas mineras cuando los filones se extinguieron. En la provincia de Ciudad Real existen igualmente casos similares de minas importantes, casi siempre de plomo con más o menos plata ${ }^{11}$, que pasan inadvertidas cuando circulamos por los alrededores y que, sin embargo, dieron lugar a pueblos, hoy desaparecidos, con muchos habitantes, como El Horcajo o San Quintín:

El cierre de los pozos vino acompañado de una brusca caída demográfica que puso punto final a la pequeña historia de San Quintín. Conjuntos de viviendas desperdigadas y completamente en ruinas, restos de las antiguas instalaciones mineras, montículos de escoria mineral y un cementerio abandonado son todo lo que queda de una etapa tan próspera como fugaz. (Trujillo Valderas, 2016, p. 29).

Aunque esta es la pauta general en lo que se refiere a minas abandonadas, hay, en cambio, algunos casos de distritos mineros importantes en los que villas y ciudades perviven después de la clausura de su actividad. Un buen ejemplo de ello son los Reales de Nueva España, los cuales comenzaron siendo pequeñas poblaciones mineras, sin estatus de villa o ciudad, pero por la importancia de sus yacimientos, que fueron explotados durante siglos, acabaron convertidos en bellas ciudades. No obstante, su urbanismo es algo desordenado, como son los casos, por ejemplo, de Zacatecas o Guanajuato. En España hay casos similares, si bien con menor riqueza arquitectónica, como son Linares (Jaén) o La Unión (Murcia), ligadas ambas durante centurias a la minería metálica, o también Almadén, cuyo caso se analiza en este artículo.

Algunos autores siguen despreciando esta arquitectura de los pueblos industriales y mineros, considerándola una arquitectura menor. Un autor anónimo escribía en julio de 2019 que Almadén es un pueblo:

carente de edificios monumentales, de casas blasonadas, de infraestructuras o de instituciones históricas, por citar algunos signos de riqueza o importancia. Que lo único reseñable como tal, la Plaza de Toros y el Hospital de Mineros, carecen de cualquier interés arquitectónico, y que su Academia de Minas, de trucada fachada en imitación de piedra, no fue sino el equivalente a una formación profesional ${ }^{12}$.

11 El mineral característico es la galena (sulfuro de plomo) argentífera.

12 Anónimo, Diario Lanza, edición digital, 6 de julio de 2019. Accesible en https://www. lanzadigital.com/blogs/cronicas-de-la-historia/la-siberia-manchega/. Recuperado el 5 de octubre de 2021. 
Ya advertía al respecto el académico Bonet Correa $(1974$, p. 83), casi medio siglo antes:

La arquitectura industrial en España constituye una parte marginada por los historiadores y críticos de arte. La razón se debe a que, salvo raras excepciones, los edificios creados para la industria se consideran excluidos de lo que se juzgan criterios únicos y sublimes de lo bello, relegando su producción a la escala menor de la meramente utilitario. Su juicio no merece casi discusión y el estudio de sus obras podrá hacer evidente su error. Pero la tarea es larga.

En otro párrafo del mismo artículo, Bonet Correa (1974, p. 88) defendía así el patrimonio industrial:

cuán grande era el empeño y el afán de los hombres del siglo XVIII, los cuales creerían firmemente que mediane el trabajo, el esfuerzo y las mejoras materiales se lograría alcanzar el progreso y la felicidad para todos los hombres [...] son obras dignas de ser colocadas tan altas dentro de la escala de valores arquitectónicos como los de un templo o las de un palacio neoclásico de la misma época. El hacerlo no supone hoy nada de extraordinario. Tampoco lo fue para algunos hombres filantrópicos del siglo XVIII, como Campomanes o Jovellanos. Para estos ilustrados el bien supremo residía en la utilidad pública y nada debiera ser más bello y cuidado que las obras de las artes útiles destinadas a fomentar el bienestar y la felicidad del género humano.

De este modo, en la segunda mitad del XVIII, la cultura ilustrada se interesó de forma preferente por todo aquello que fuera capaz de mejorar la condición humana y la felicidad pública, para que así los ciudadanos libres fueran gobernados por leyes justas.

El presente artículo intentará demostrar cómo y por qué Almadén se convirtió con el paso de los siglos en una importante villa minera, si bien hubo que esperar a la segunda mitad de la centuria del XVIII para que su urbanismo mejorara enormemente con la construcción de nuevas casas y el empedrado de las calles, y para que se levantaran en el exterior del recinto minero los mejores edificios de la localidad. Por tanto, no se analizarán en este artículo los edificios de máquinas, castilletes y hornos existentes dentro del gran cerco de piedra y ladrillo que rodea el establecimiento minero, ni tampoco las labores subterráneas de los siglos XVI al XVIII que causan la admiración del visitante al Parque Minero de Almadén. Para conseguir el objetivo señalado con anterioridad se describirá brevemente la historia común de la mina y de la localidad de Almadén para pasar posteriormente a la investigación causal del auge urbanístico de la segunda mitad del XVIII, incluyendo los grandes edificios que se hallan dispersos en el casco urbano y que, como se verá, tenían distintas funciones que cumplir. 
Las aportaciones más interesantes sobre el urbanismo de Almadén son las de Rafael Sumozas García-Pardo (2007 y 2012) y Rafael Gil Bautista (2013 y 2015), si bien son fundamentalmente descriptivas, sin profundizar en las causas del apogeo urbanístico de la segunda mitad del XVIII. Además, el artículo ya citado de Antonio Bonet Correa, breve pero relevante sobre el asunto de que se trata. Sobre el urbanismo en general durante la edad Moderna en España hemos consultado el libro de María del Mar Lozano Bartolozzi (2011). Para contextualizar el tema se resumirán los sucesos más importantes de la historia de Almadén y su mina de azogue, poniendo especial énfasis en la edad Moderna. El autor de referencia es Antonio Matilla Tascón (1958 y 1987), si bien se han utilizado también textos de otros autores, como Eugenio Larruga (1792). Respecto a las enfermedades de los mineros de Almadén, la aportación clave es la de Alfredo Menéndez Navarro (1996) y para las innovaciones organizativas, técnicas y laborales la de Rafael Dobado González (2000). Diversos datos sobre la mano de obra forzada utilizada en la mina proceden de Ángel Hernández Sobrino (2010). También se ha recurrido a fuentes manuscritas procedentes de diversos archivos, sobre todo el Archivo Histórico Nacional, donde hay un fondo específico sobre Minas de Almadén; el Archivo General de Indias; el Archivo Central y Biblioteca del Ministerio de Economía y Hacienda; y, por último, el Instituto de Historia y Cultura Militar, que custodia el extenso informe sobre las minas de azogue realizado en 1754 por el ingeniero militar Silvestre Abarca ${ }^{13}$.

\section{DESDE LA ÉPOCA ÁRABE HASTA LA ILUSTRACIÓN}

Bajo las casas de Almadén se albergaba el mayor yacimiento de mercurio del mundo, ya que su mina ha producido nada menos que la tercera parte del consumido por la humanidad a lo largo de toda su existencia. Las primeras pruebas fehacientes de la explotación del yacimiento de Almadén corresponden a la época de dominación musulmana, si bien queda claro que los romanos extrajeron cinabrio de esta zona de España para llevarlo a Roma y fabricar bermellón con él. El yacimiento explotado en la época romana no fue Almadén sino Las Cuevas, situado a unos ocho kilómetros, en línea recta, al nordeste de Almadén (Hernández Sobrino et al., 2017, p. 246). En la mina de Las Cuevas han aparecido diversas labores subterráneas y a unos doscientos metros de la entrada del socavón que conduce a las mismas los restos de un poblado. Tampoco hay ningún resto visigótico en el mismo Almadén, si bien han aparecido vestigios de una pequeña basílica, restos de un poblado y un cementerio en el Pilar de la Legua, un área situada a unos cinco kilómetros al este de Almadén. En cambio, en la parte más elevada del cerro en el que está situado

${ }^{13}$ Lamentablemente no hemos podido consultar el Archivo Histórico Municipal de Almadén, pues permanece cerrado al público. 
esta población aparecen los restos de un pequeño castillo árabe, probablemente del siglo $x$. «Al-maaden» significa, en árabe, la mina y su azogue fue utilizado sobre todo en aquella época para la alquimia y la medicina. En todo caso debió ser una explotación minera de poca importancia, realizando solo pocillos y trincheras de poca profundidad sobre los bancos de mineral (Fotografía 1).

La zona de Almadén pasó a manos cristianas de manera definitiva después de la batalla de Las Navas de Tolosa en 1212 y Alfonso X el Sabio confirmó en 1254 la donación de la mitad de la mina de Almadén, hecha por Fernando III en 1249, a favor de la Orden de Calatrava (Matilla Tascón, 1958, p. 267). En 1282, por privilegio del infante Sancho IV, se hizo donación a dicha Orden de la otra mitad de la mina de Almadén (Ibid, p. 271) y solo cuatro años después se autorizó a los caballeros calatravos a fabricar y vender bermellón (Ibid, p. 273).

Como los caballeros calatravos desconocían el negocio minero, decidieron alquilar la explotación del yacimiento a comerciantes catalanes y genoveses e incluso al propio rey Alfonso XI. Así fue transcurriendo la centuria del XIV hasta que a comienzos del siglo xv la Orden decidió convertir a Almadén, para que se poblase, en un lugar exento de su jurisdicción, excepto el pago de diezmos. Para ello, el maestre de la Orden, Don Luis de Guzmán, con los caballeros, comendadores y priores de Calatrava, aprobaron el 22 de marzo de 1417 su fuero de repoblación. Dicho fuero:

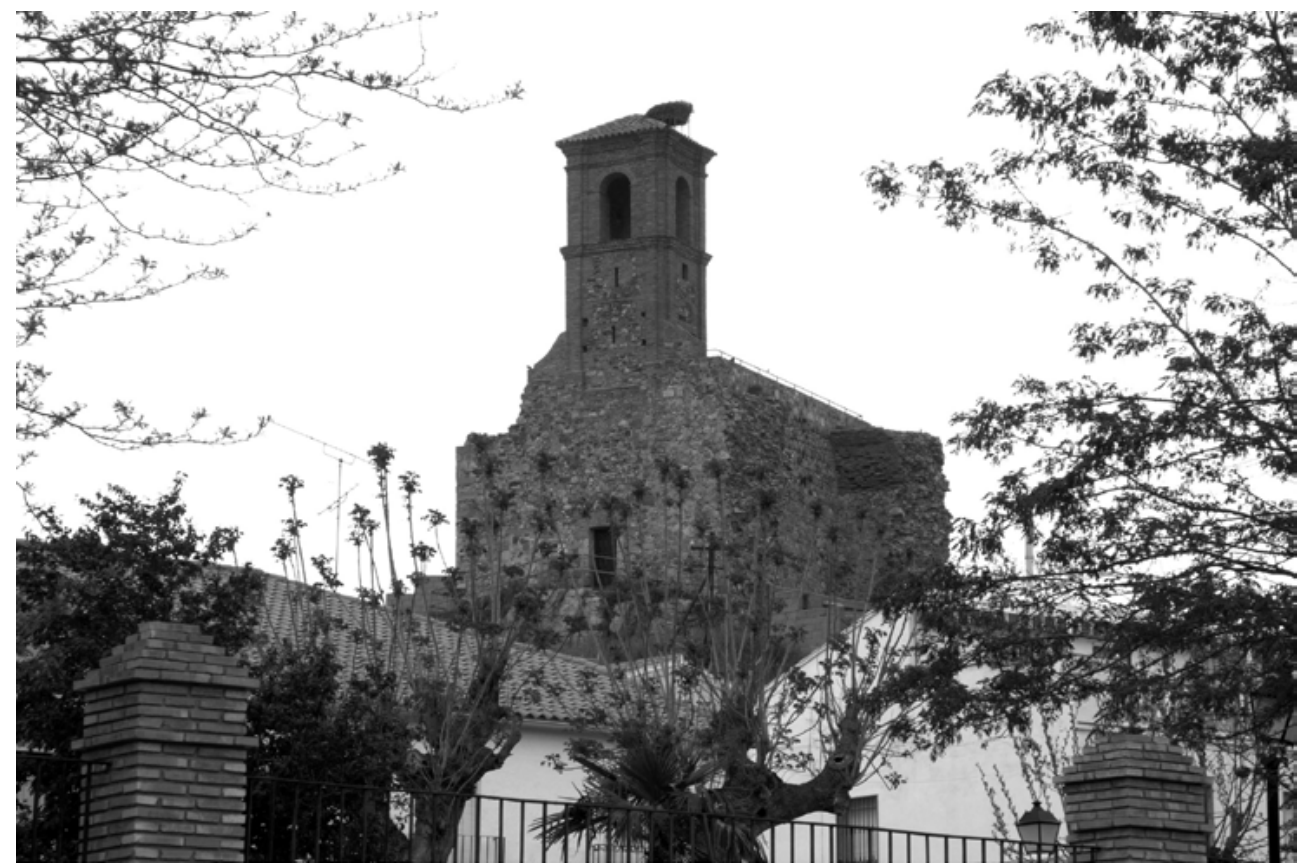

Fotografía 1. Ruinas del castillo árabe. Fuente: García-Rayo, 2020 
«procura la población necesaria al nuestro lugar de Almadén, el cual está despoblado por mengua de privilegios [...] porque se puede bien poblar y restaurar según que al bien de dicha nuestra Orden conviene, por ende, por hacer bien y merced de dicho nuestro lugar del Almadén y a los vecinos y moradores de él y de sus términos, que ahora son o sean de aquí adelante» (Ibid, p. 312) ${ }^{14}$.

Nuevos arriendos se sucedieron a lo largo del siglo XV, mientras que Almadén continuaba siendo un pequeño asentamiento minero de poca importancia, donde había unas explotaciones reducidas y unos hornos de origen árabe, conocidos como jabecas, en los que una parte del mineral se transformaba en azogue ${ }^{15}$. A finales de la centuria del XV, los Reyes Católicos maniobraron con el Papa de Roma para hacerse con los bienes de las Órdenes Militares y acabar así con los últimos baluartes del feudalismo medieval; por fin, consiguieron su propósito cuando Inocencio VIII prohibió en 1487 a los caballeros de Calatrava elegir nuevo maestre de la Orden. Entre los bienes logrados estaba Almadén, que en ese período finisecular producía un centenar de quintales castellanos anuales de azogue ${ }^{16}$.

En 1523, la administración vitalicia de los bienes de las Órdenes Militares se transformó en perpetua, cuando Adriano VI los vinculó a la Corona de España. Por entonces entraron en escena los Fugger o Fúcares ${ }^{17}$, banqueros alemanes que tuvieron en asiento los maestrazgos de las Órdenes Militares de Santiago, Alcántara y Calatrava, incluyendo en este último Almadén. De esta manera, Carlos $V$ compensó el apoyo económico de los Fugger ante el colegio de príncipes electores para ser elegido emperador del Sacro Imperio. Los Fugger administraron la mina de azogue de forma prácticamente continua entre 1525 y 1645, y al poco de su llegada, la producción de azogue empezó a aumentar, de modo que la media anual del período de 1547 a 1550 fue ya de 1000 quintales, es decir, diez veces más que la de principios de siglo. Ello fue debido a que trajeron algunos expertos de las minas que tenían en el Tirol, al igual que hicieron en la mina de plata de Guadalcanal (Sevilla), también administrada por los Fúcares (Sánchez Gómez, 1989, pp. 417-452).

La producción de azogue habría sido mayor si hubiera habido suficiente mano de obra, pues los Fúcares dispusieron de expertos que sabían utilizar la brújula y dibujar planos de la mina, como Sebastián Curtio, quien delineó en 1543 el plano de las labores subterráneas más antiguo que se conserva. Los accidentes y las enfermedades no hacían apetecible el oficio de minero, así que los forasteros no querían asentarse en Almadén. A los accidentes e incendios que ocurrían en la mina

${ }^{14}$ Este es un tema recurrente a lo largo de los siglos, pues hasta la segunda mitad del XVIII nunca se consiguieron en Almadén suficientes operarios para la explotación de la mina.

${ }^{15}$ Con la parte restante se fabricaba bermellón.

${ }^{16}$ Un quintal castellano pesa 46 kilogramos, el equivalente, a cuatro arrobas.

17 Fúcares es el nombre castellanizado de Fugger y, por tanto, el más usado en los reinos de España. 
se unían las enfermedades de los mineros, conocidas desde antiguo y producidas por la aspiración del vapor de mercurio, tanto por los que trabajaban en el interior de la mina como los que lo hacían en los hornos de tostación del cinabrio. Además, Almadén era la mina más perjudicial de todas ellas, ya que a diferencia de Idria, en el antiguo reino de Hungría, y Huancavelica, en el virreinato del Perú, aparecía azogue virgen en sus labores subterráneas, con lo que la posibilidad de intoxicarse con sus vapores era mayor. El otro gran enemigo de los mineros de Almadén era el polvo de sílice, el cual se introducía en sus pulmones al respirar, produciendo silicosis, si bien esta enfermedad fue confundida durante siglos con la tisis o tuberculosis pulmonar ${ }^{18}$. No es por tanto de extrañar que, ante tantos peligros, nadie quisiera ser minero de Almadén.

Un grave incendio ocurrido en el interior de la mina en 1550 alejó momentáneamente a los Fúcares del asiento de la mina de Almadén y cuando lo recuperaron ya había ocurrido en Nueva España un acontecimiento trascendental. En efecto, Bartolomé de Medina, comerciante sevillano, había puesto a punto en 1554 el proceso industrial de la amalgamación. El experimento se había realizado en el patio de una hacienda de la mina de plata de Pachuca, en el que el mineral de plata había sido molido y mezclado íntimamente con azogue, formando una amalgama de ambos elementos $^{19}$. La amalgamación se extendió rápidamente por toda Nueva España y en 1570 llegó a Potosí, en el virreinato del Perú, que por entonces era la mayor mina de plata del mundo. La repercusión de la amalgamación en Almadén fue enorme, pues la otra gran mina de azogue del imperio, Huancavelica, bastante tenía con abastecer a Potosí, así que Almadén se obligó a aprovisionar a Nueva España.

Los Fugger tenían un difícil reto por delante, pues, aunque no habían obtenido el arriendo de los maestrazgos ni de la mina de azogue desde 1550, habían continuado prestando dinero a las deterioradas haciendas de Carlos I y Felipe II, de modo que en 1560 la Corona les debía ya casi tres millones de ducados. Como continuaba la escasez de mineros libres, los Fugger solicitaron a Felipe II el envío de galeotes o forzados para trabajar en Almadén, pero llegaron con cuentagotas, ya que tenía prioridad el remo en las galeras del Mediterráneo para la lucha contra los turcos. Entonces, los Fugger pidieron a la Corona que mandara moriscos desterrados de Las Alpujarras, pero ni ellos venían a gusto a trabajar en las labores subterráneas ni tampoco los recibieron bien los cristianos viejos de Almadén ${ }^{20}$. La mejor solución

${ }^{18}$ La roca que contiene el cinabrio en Almadén es una cuarcita, la cual tiene más de un $80 \%$ de sílice en su composición.

${ }^{19}$ Este procedimiento permitió aprovechar el mineral de plata de baja ley, que no era rentable para fundirlo directamente. La amalgamación es, pues, un proceso de concentración del mineral pobre con azogue.

${ }^{20}$ Hasta tuvo que intervenir Felipe II para ordenar que el alquiler de las casas y las provisiones no se les encarecieran a los moriscos y que no se les sometiera a vejaciones ni molestias (Matilla Tascón, 1958, pp. 95-97). 


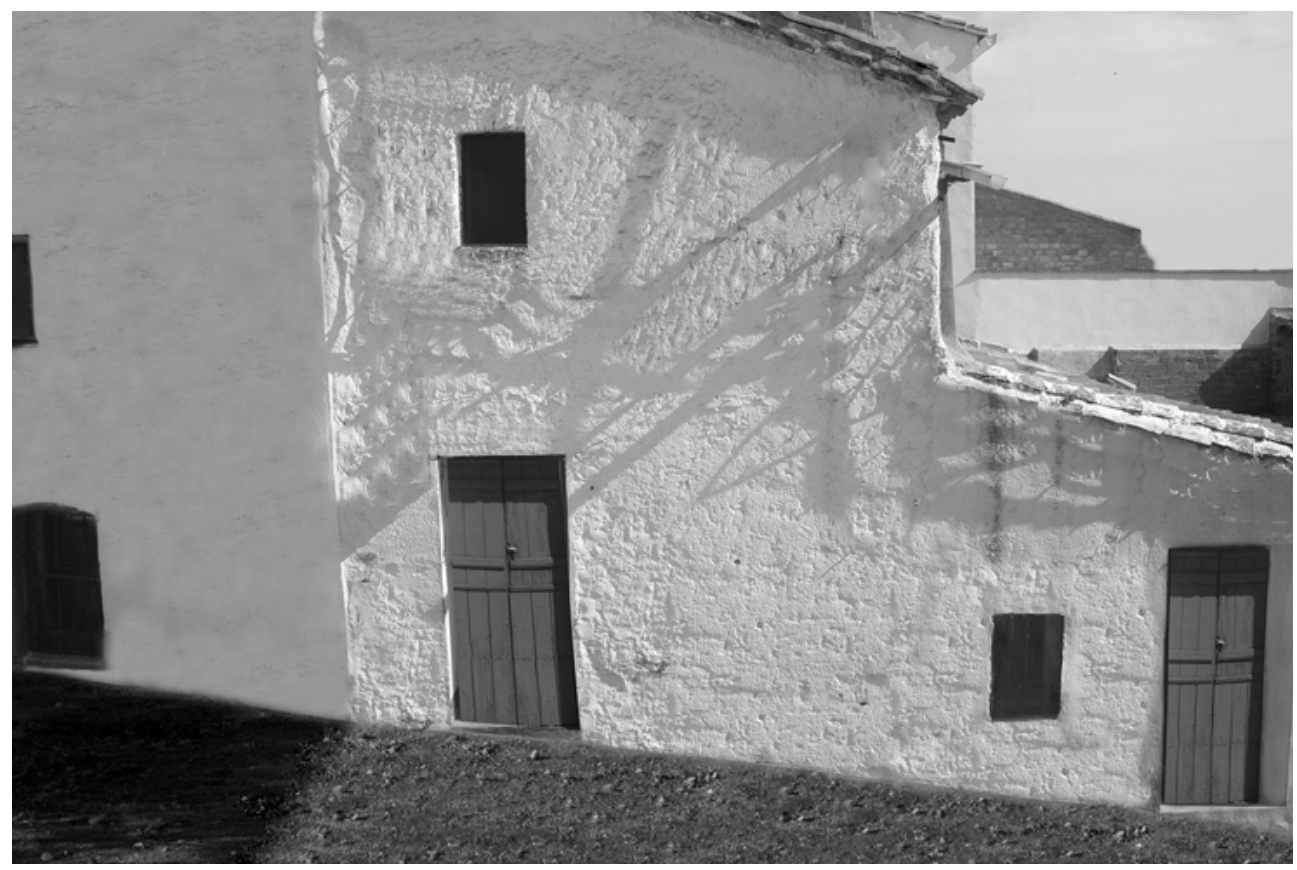

Fotografía 2. Casas del barrio morisco o barrio nuevo de Almadén. Fuente: García-Rayo, 2021

hubiera sido comprar esclavos, quienes vendrían de por vida a la mina, pero los Fugger no querían hacer grandes desembolsos, así que continuó sin solucionarse el problema de la mano de obra ${ }^{21}$ (Fotografía 2).

Otro intento de solución del problema citado consistió en la exención de tributos a los mineros de Almadén. Así, en 1573, el rey ordenó que:

por razón de la necesidad que ahora hay de más gente para que trabajasen en la dicha fábrica, por haber aquella crecido y aumentándose tanto, [...] tenemos por bien y concedemos que todas las personas que trabajaren y sirvieren en el dicho pozo y mina del Almadén y fábrica de él [...] hayan de ser y sean libres y relevados de pagar, y que no paguen ni se les repartan el tiempo que sirvieren en el dicho pozo y fábrica ningunos pechos ni derechos de los en que contribuyen los buenos hombres pecheros de la dicha villa del Almadén ni los cobren de ellos. (Dobado González, 2000, p. 385).

${ }^{21}$ La existencia de Almadén solo estaba justificada por la mina de azogue y las otras actividades económicas tenían muy poca importancia. Por ello, la subsistencia de casi todas las familias dependía de los jornales de mina, llegando incluso a prohibir establecerse en Almadén a aquellos forasteros que no quisieran trabajar en las labores subterráneas (Dobado González, 2000, p. 429). 
Además, Felipe II mandó también en dicha fecha que para que los mineros no se ausentaran de su puesto de trabajo ni tuvieran problemas de suministros, se permitiera que en el propio establecimiento minero o en un lugar cercano: «se pueda tener y tenga provisión de carnicería y pescadería y vino y pan y las otras cosas y mantenimiento necesarios para la provisión y sustento de la gente que trabajase en el dicho pozo y fábrica» (Ibid., p. 386).

Pese a las anteriores ventajas, Almadén continuaba siendo un villazgo pobre en el que los Fugger veían solo una oportunidad de negocio, que consistía en obtener el mayor margen posible entre el coste de producción del azogue y bermellón, y el precio de venta de ambos a la Corona. Por ello, cuando se llevó a cabo en 1575 las Descripciones de los pueblos de España, en lo que se refería a Almadén se afirmaba que:

las casas de la villa y edificios son malos y pequeños; son de piedra y barro y de encina de esta sierra, y algunos hay de cal y de ladrillo [...] hay cuatrocientas casas y con una aldea que se dice Gargantiel y otra que se dice Alamillo habrá en todo cuatrocientos cincuenta vecinos poco más o menos [...] y también los más son trabajadores de las minas y pozo de azogues que S.M. tiene aquí. (Real Academia de la Historia, 1575, ff. 194-199v).

A muchos pueblos de España le ocurría lo mismo que a Almadén, pues conservaban de la edad Media su trazado irregular andalusí, cristiano y mudéjar, condicionado por la topografía, las curvas de nivel y la densidad demográfica, con calles angostas en las que había poca ventilación y muchos quiebros (Lozano Bartolozzi, p. 122).

En cuanto a la mano de obras, a los mineros libres se añadían unas pocas decenas de forzados y esclavos, siempre muchos menos de los necesarios para dar la producción de azogue que necesitaban en Nueva España, desde donde además solicitaban que se bajara su precio ${ }^{22}$. En 1590, el virrey se dirigió a Felipe II para indicarle que: «cualquiera merced que a los mineros hiciere ha de resultar en acrecentamiento de la Real Hacienda, porque se beneficiarán más minas y se sacará más plata, y de ella serán mayores las rentas de quintos, diezmos y derechos ${ }^{23}$.

Sucesivos asientos les fueron concedidos a los Fugger en la última década del XVI y primer cuarto del XVII, mas ni la Corona ni los Fugger invertían lo necesario en Almadén, ni en la mina ni en la población. La producción de azogue fue ascendiendo

${ }^{22}$ El aumento de la producción de azogue en Almadén a finales del XVI permitió disminuir su precio en Nueva España hasta los 110 pesos por quintal en 1602. En los años siguientes llegó a bajar hasta 60 pesos, pero en 1617 se fijó su precio en 82 pesos y así siguió hasta 1767.

${ }^{23}$ AGI, MEXICO, 22, N. 19. Carta del virrey Luis de Velasco a S.M., México, 6 de junio de 1590. 
lentamente, de los 3000 quintales anuales a los 5000, pero todavía muy lejos de los pretendidos 10000 que Juan de Pedroso, visitador enviado por la Corona a Almadén en 1613 , fijó como objetivo ${ }^{24}$. Las labores subterráneas eran cada vez más profundas y el aire puro llegaba con mayor dificultad, lo que incrementaba el hidrargirismo y las enfermedades respiratorias de los mineros, y ahuyentaba a los forasteros de Almadén. Lo que sí continuaba habiendo eran exenciones de impuestos para muchos trabajadores (300 de ellos en 1615) y otras exenciones generales de quintas, bagajes, impuestos y cargas concejiles, así como no tener que dar alojamiento a soldados ni otra gente de guerra. En esa época trabajaban en la mina unos 600 operarios fijos y otros tantos más en la temporada invernal, que era cuando los hornos estaban en funcionamiento, pues con la llegada del calor se suspendían las operaciones de tostación del mineral. Entonces, muchos trabajadores abandonaban temporalmente Almadén para ocuparse en faenas agrícolas ${ }^{25}$.

Aunque se necesitaban más operarios para aumentar la producción, lo cierto es que no había suficientes casas para albergarlos. Cuando los moriscos fueron expulsados de España en 1609, los que vivían en Almadén hubieron de abandonar sus casas y: "como lo ha mostrado la experiencia en ochenta casas que quedaron vacías por los moriscos, sin que una tan sola esté desocupada ni la haya en todo el lugar, antes en algunas hay dos moradores» (Larruga, 1792, p. 119). En 1610 se había hecho un plan por orden de S. M. para construir doscientas casas y entre ellas seis $\mathrm{u}$ ocho de mayor tamaño para que sirvieran como posadas y bodegones, pero el coste de cada casa era muy alto, unos 400 ducados, así que la Corona intentó que los Fugger prestaran el dinero necesario a los forasteros y que estos se lo devolvieran poco a poco. Los arrendatarios se mostraron remisos a esta operación financiera porque un préstamo tan grande era difícil de reembolsar en solo cuatro años, que era cuando finalizaba su asiento, año 1614, sin tener seguridad de su renovación ${ }^{26}$.

La situación económica empeoró radicalmente en el asiento de 1625 a 1635, pues la Corona suspendió pagos debido a la grave crisis económica que aquella atravesaba. Aunque había habido diversas bancarrotas anteriores, los Fugger habían salvado sus créditos, recompensando así la Corona sus buenos servicios por los numerosos préstamos de 100000 a 150000 ducados para el mantenimiento de

${ }^{24}$ Hay que tener en cuenta que la Corona era la propietaria de la mina, por lo que cada cierto tiempo enviaba a Almadén a alguien de su confianza para comprobar que los Fugger explotaban el yacimiento de manera adecuada.

25 Por ejemplo, en 1621 había unos 1200 operarios libres y unos 130 obligados. De los libres, 750 trabajaban en las labores subterráneas, 150 en las operaciones metalúrgicas y otros 270 en cortar y traer leña menuda y maderos de las dehesas cercanas a la mina. Además, había 128 obligados, 40 forzados y 88 esclavos, lo que hacía un total de 1298 operarios (Matilla Tascón, 1958, p. 165).

${ }^{26}$ Un minero de Almadén ganaba solo de media 4 reales por jornal y no daba más allá de diez jornales al mes para no enfermar, así que tardaría nueve años en ganar 400 ducados. 
las tropas en los Países Bajos. Entre 1626 y 1630 hubo un alza en el precio de los jornales del campo y demás trabajos de casi el $50 \%$, por lo que también subieron los jornales de la mina. Pese a ello, los Fugger intentaron resistir y en el período de 1625 a 1634 produjeron una media de 4518 quintales de azogue al año. No obstante, las necesidades americanas eran mucho mayores, por lo que la Corona hubo de adquirir azogue en Idria, propiedad por entonces de la Corona austríaca ${ }^{27}$.

Los negocios de los Fugger con la Corona no se limitaron a los Maestrazgos y Almadén, sino que realizaron numerosas operaciones financieras con los tres Felipes, consistentes en suculentos préstamos para la Cruzada, la Casa Real u otros fines. Cuando llegaban los vencimientos de las libranzas, los Fugger encontraban siempre dificultades insuperables para hacerlas efectivas. La deuda había crecido tanto que Felipe IV comprendió que no podría contar con ellos para sus futuros compromisos y los Fugger suspendieron pagos en $1631^{28}$. Aun así, hicieron un intento desesperado por continuar sus negocios en España y firmaron un nuevo asiento, el último, para el decenio 1635-1645, pero en franca bancarrota no pudieron hacer frente a los gastos de la mina y la producción de azogue descendió a la mitad ${ }^{29}$. Pese a la diligencia y reiteración con que Andrés Hyrus, nuevo factor de los Fúcares escribió incontables memoriales para intentar resolver los conflictos planteados, no hubo solución posible. Los Fugger abandonaron Almadén en 1645, devolviendo así la administración directa de la mina de azogue al Consejo de Hacienda.

Entre los bienes que dejaron había diversas casas en el exterior del recinto minero y en su descripción aparecen términos como "casas pequeñas y casas viejas», lo que confirma nuestra hipótesis de que no construyeron ningún edificio relevante. Ni siquiera la cárcel de forzados y esclavos estaba bien edificada, lo que favorecía la fuga de los presos. Además, al no disponer de excretas, se provocaban frecuentes episodios de paludismo. Los Fugger también dejaron atrás la capilla de San Juan, construida para la asistencia espiritual de los mineros y a cuyo capellán abonaban 600 reales anuales ${ }^{30}$. La citada capilla es un edificio modesto con planta de cruz griega y construida en piedra y ladrillo, en nada comparable a la capilla del Señor San Salvador ${ }^{31}$, construida en Almagro. En dicha villa de la Orden de Calatrava, los

27 Sucesivos asientos con diversos intermediarios permitieron la adquisición de 72000 quintales de azogue de Idria entre 1621 y1646. El azogue era enviado por mar de Trieste a Cádiz, para luego ser transportado a América con el de Almadén (Matilla Tascón, 1958, pp. 224-233)

${ }^{28}$ En el reinado de Felipe IV más de la mitad de la plata americana se dedicó a cancelar las deudas que la Corona tenía con sus prestamistas, lo que da idea de la gran importancia que tuvieron esos fondos como garantía del crédito de la monarquía (Álvarez, 1997, p. 67)

29 La producción media anual entre 1636 y 1645 fue solo de 2.535 quintales de azogue, por lo que la Corona continuó adquiriendo azogue a Idria (Matilla Tascón, 1958, p. 182).

30 Once reales valían un ducado.

${ }^{31}$ La capilla de San Salvador, conocida hoy en día como la ermita de San Blas, está construida en mampostería y su estilo es gótico, con decoración renacentista de raíz plateresca. 
Fugger edificaron además las casas de sus administradores y el almacén-factoría de los Maestrazgos. Se puede concluir, por tanto, que, a mediados del siglo XVII, el urbanismo de Almadén continuaba en un estado deplorable, impropio: "de la importancia grande de la mina del Almadén, por el azogue que en ella se saca para remitir a las Indias, con que se beneficia la plata que viene de ellas a estos reinos y el gran beneficio de la Real Hacienda ${ }^{32}$.

La segunda mitad de la centuria del XVII fue todavía peor que la primera, pues la cobranza de las consignaciones para la mina se hacía con mucho retraso, no pudiéndose abonar el salario a los mineros a su debido tiempo, lo que retrajo aún más a los forasteros para asentarse en Almadén ${ }^{33}$. Además de los forzados y esclavos, tan escasos por los problemas comentados con anterioridad, se utilizó un nuevo método para conseguir brazos para la mina, el llamado repartimiento, una especie de mita de los jóvenes de algunos pueblos cercanos a Almadén, a cambio de exenciones militares y fiscales (Silvestre y Almansa, 2019, p. 349). Este sistema provocó que el Consejo de Guerra enviara una queja al de Hacienda por las excusas que presentaban estos pueblos para no contribuir al Ejército de Extremadura ${ }^{34}$ (Ibid, p. 351).

Esperar a que la situación económica de Almadén fuera insostenible para enviarle auxilios momentáneos era una mala política y había perjudicado mucho la conservación de la mina y la producción de azogue. Pese a que en 1672 el Consejo de Hacienda planteó evitar estos males con una consignación fija suficiente, la propuesta corrió la suerte de tantas otras. Por ello, las producciones anuales de azogue eran muy bajas y cuando en 1678, el Consejo de Hacienda consultó acerca de cuánto azogue se podría beneficiar en ese año, el administrador de la mina le contestó que sería de 1700 a 1800 quintales, es decir, una cantidad similar a la que se producía un siglo antes (Larruga, 1792, p. 191). Con unas labores subterráneas que superaban los 120 metros de profundidad, la ventilación era muy deficiente en el fondo de la mina, a pesar de los fuelles utilizados para dar aire a las labores subterráneas. A ello se añadía el retraso en la paga de los operarios, así que la producción anual de azogue no superó los 3000 quintales en la segunda mitad del XVII ${ }^{35}$. Mientras tanto, Carlos II se lamentaba: «de la falta que se experimenta en asistir a las personas que sirven en las minas del Almadén y del evidente riesgo en que se

${ }^{32}$ Consulta del Consejo de Hacienda a S. M., 28 de febrero de 1654 (Larruga, 1792, p. 173).

${ }^{33}$ Almadén tenía por entonces 470 vecinos, de los que 300 estaban libres de impuestos por ser mineros (Matilla Tascón, 1958, p. 136), al igual que otros 16 clérigos y 80 viudas, así que solo había 74 pecheros. Estas cifras, en las que forzados y esclavos no están incluidos, demuestran que Almadén perdió población en esos años.

${ }^{34}$ Portugal se había levantado en armas contra España en 1640 y la paz no llegó hasta 1668.

${ }_{35}$ Menos mal que Huancavelica atravesaba una buena época en el último cuarto del siglo XVII, produciendo 70000 quintales de azogue entre 1680 y 1699, mientras que Almadén solo produjo la mitad. 
hallan de perderse, de que resultaría tanto perjuicio, pues faltarían azogues para el beneficio de la plata en Nueva España» ${ }^{36}$.

A finales del XVII se descubrió una nueva zona mineralizada en el yacimiento de Almadén, lo que supuso un enorme alivio en la explotación, ya que se encontraba muy cercana a superficie y, por ende, se consiguió aumentar considerablemente la producción de azogue con el mismo número de operarios. No obstante, no hubo mayor repercusión de esta nueva área minada, conocida como mina del Castillo, en el urbanismo almadenense, tal y como demuestra esta Acta Municipal de 1718 en la que se acuerda adecentar: «las calles públicas de esta villa y especialmente las de mayor comercio y paso de las procesiones tienen muchos barrancos y están desempedradas gran parte de ellas» ${ }^{37}$ (Gil Bautista, 2013, p. 66). En 1733, la situación seguía igual o peor, por lo que el Ayuntamiento obligó a los vecinos a colaborar económicamente en su reparación (Ibid., pp. 66-67). Además, el hecho de que la mina del Castillo estuviera bajo la población provocaba a veces daños adicionales en calles y viviendas por la utilización de pólvora en las labores subterráneas. Esta había sido introducida en Almadén a finales de la centuria anterior y durante el XVIII se hubo de indemnizar a los vecinos en varias ocasiones por aparecer grietas y otros desperfectos en sus casas.

Otro aspecto, a destacar, a comienzos del XVIII, es el final del enfrentamiento entre el Consejo de Hacienda y el de Indias para el gobierno de las minas de azogue, de modo que el segundo desplazó definitivamente al primero. En 1708 se creó la Junta de Azogues, lo que venía a inclinar la balanza a favor del Consejo de Indias, y en 1717 sería la Superintendencia General de Azogues el organismo encargado de las minas de Almadén hasta 1790, cuando volverían a depender de Hacienda. En el período que transcurre entre 1754, cuando la Superintendencia General de Azogues fue adscrita a la Secretaría de Estado y del Despacho Universal de Indias, y 1790 se acumularon diversas medidas tendentes a eliminar los obstáculos financieros, laborales y técnicos que impedían el incremento de la producción de azogue para satisfacer la demanda de las minas de plata de Nueva España (Dobado González, 2000, p. 421).

\section{LA SEGUNDA MITAD DEL XVIII}

A mediados del siglo XVIII se produjo en Almadén un cambio radical respecto a la época anterior. Aunque el movimiento ilustrado se dejaba ya notar desde principios de la centuria con la llegada de la nueva dinastía borbónica a nuestro país, fue durante los reinados de Fernando VI, Carlos III y Carlos IV cuando eclosionó

${ }^{36}$ Real Orden de Carlos II, Buen Retiro, 11 de abril de 1679 (Larruga, 1792, pp. 202-203).

37 Archivo Municipal de Almadén (AMA), legajo 32, Libro de Acuerdos 11. 
con toda su fuerza. En esta época se unió la mentalidad ilustrada a la ciencia y a la técnica, permitiendo conocer y controlar el territorio bajo un sistema globalizador y centralista (Lozano Bartolozzi, p. 76). Esta implicación de la monarquía y sus gobiernos ilustrados no solo se dejó notar en la política, la economía y la sociedad sino también en las ciencias y las técnicas, entre otras la minería, y por tanto en Almadén. Cuando en 1749 se nombró por el marqués de la Ensenada, ministro de Marina e Indias, como superintendente de las minas y gobernador de Almadén a Francisco Javier de Villegas, este pronto se dio cuenta: «que sería muy conveniente enviasen Personas que supiesen levantar Planos de las Minas y dar sus Direcciones [...] se me mandó venir a la Corte en Agosto del mismo año (1750) e inmediatamente se nombraron Maestro mayor y teniente de Minas» ${ }^{38}$.

El médico ilustrado José Parés y Franqués ${ }^{39}$, quien cuidó de la salud de los mineros de Almadén durante 37 años (1761-1978), asistió en primera fila a este profundo cambio de mentalidad que había terminado con las dificultades económicas del siglo XVII, cuando los operarios no cobraban los salarios a su debido tiempo y muchos hubieron de emigrar. En cambio, en la segunda mitad del XVIII, hombres como Ensenada, Arriaga o Gálvez fueron conscientes de que las consignaciones para Almadén debían ser lo más generosas posibles:

se le han asignado a nuestras minas seis millones de reales de vellón anuales, en lo que se benefician Minas y Mineros [...] Esta asignación proporciona al presente provisión de Artífices hábiles, que conspiran a la mayor seguridad de las labores, medios más ciertos para el disfrute y de menor riesgo para los operarios, y últimamente Academia Mineralógica, que perpetúa la inteligencia de este Arte, propagándose de unos a otros sucesivamente; todo en utilidad de las labores interiores y de los que las manejan. (Parés, 1785, ff. 161v-162v).

De este modo, los operarios de las minas estaban dispuestos a sacrificar su salud e incluso su vida a cambio de un salario apropiado y de una vivienda digna:

Animosos mineros de Almadén, vosotros que en servicio del Rey nuestro señor (Dios le guarde) exponéis vuestra salud y vida en los peligros de estos subterráneos, contrayendo enfermedades rigurosas y hallando muchas veces la muerte en vuestros ejercicios [...] Siempre ha sido nuestro señor don Carlos Tercero magnificientísimamente (sic) piadoso. Pero lo mismo fue hacerle a Su Majestad relación puntual de nuestros servicios el Excelentísimo señor don José de Gálvez, que excederse a su mismo Real Pecho en donaciones, honores y privilegios, que os tienen lustrosamente distinguidos

38 Archivo Histórico Nacional (AHN), Fondos Contemporáneos-Minas Almadén (FC-MA), legajo 1556. Noticia de las Minas de Almadén y sucesos más notables que han ocurrido en ellas [...], Almadén, sin fecha.

39 Para la biografía de Parés véase Gil Bautista, 2009. 
y beneficiados entre cuantos están ocupados en su Real Hacienda. (Parés, 1788, ff. 623r-625r).

A partir de entonces, la producción de azogue creció de forma vertiginosa en la segunda mitad del XVIII, lo que, además, vino acompañado de un fuerte ímpetu urbanístico. En este medio siglo no solo aumentó considerablemente la construcción de casas, sino que se levantaron los edificios más representativos de la población: la Plaza de Toros, la Real Cárcel de Forzados y Esclavos, el Real Hospital de Mineros y la Academia de Minas.

El Catastro de Ensenada, realizado en 1752, indica que en Almadén había 439 casas, 533 si contamos sus aldeas de Alamillo y Gargantiel ${ }^{40}$. El número de vecinos ascendía a 822, lo que prueba que en la mayoría de las casas habitaban dos familias, y los habitantes eran $2777^{41}$. En 1761, las casas eran 584,686 con las aldeas, los vecinos 1018 y los habitantes $3636^{42}$. Solo tres años después las casas ya eran 640, los vecinos 1068 y los habitantes, $3916^{43}$. El incremento continuó imparable hasta el final de la centuria, de manera que, en el censo de Floridablanca, año 1787, los datos reflejan 6271 habitantes, así que la población de Almadén en solo 35 años, de 1752 a 1787, se había multiplicado por 2,26 (Gil Bautista, 2013, p. 145). Era evidente la necesidad de mejorar el urbanismo de Almadén, construir nuevas casas y empedrar sus calles principales, pues quedaba claro que los forzados estaban siendo sustituidos por forasteros, quienes voluntariamente venían a ejercer de mineros ${ }^{44}$.

El escaso vecindario de Almadén, "la falta de gente», había constituido un continuo problema en casi toda la Edad Moderna, de manera que faltaban brazos para trabajar en la mina. Por ello, en el último tercio del XVIII se adoptó un nuevo conjunto de medidas para favorecer la expansión demográfica de Almadén, como la ampliación de las exenciones militares y fiscales a vecinos y temporeros que tuvieran el oficio de mineros, la fundación de un montepío para los trabajadores cualificados, la extensión de limosnas a las viudas y huérfanos de los operarios, y otras. Este modelo de intervención estatal fue característico de Almadén y carece de otros exponentes en la España de la época, lo que refleja muy bien la importancia del azogue.

40 Para la evolución demográfica de Almadén entre 1752 y 1787, véase Gil Bautista, 2013, p. 134-148.

${ }^{41}$ AHN, FC-MA, legajo 1307.

42 Ibid.

${ }^{43}$ AHN, FC-MA, legajo 621.

${ }^{44}$ En 1782 había ya solo 97 forzados y en 1789, el número había descendido a 34 . Aunque en 1792 volvió a haber 83, la Real Cárcel fue clausurada por fin en 1799 (Hernández Sobrino, 2010, p. 335). 
A mediados del siglo XVIII, la minería de la plata en Nueva España comenzaba su época de apogeo. Muy atrás quedaban ya los años en que sus yacimientos eran tan ricos que no necesitaban azogue para amalgamar el mineral antes de su introducción en los hornos. El binomio Almadén-Nueva España iba a sustituir al de Huancavelica-Potosí, situado en el Perú ${ }^{45}$. El Cerro Rico de Potosí había sido la mayor mina de plata del mundo en los siglos XVI y XVII, pero daba ya graves síntomas de agotamiento al igual que Huancavelica, cuya producción de azogue había descendido mucho ${ }^{46}$. Sin duda, había llegado el momento de que Almadén hiciera frente al reto que se le presentaba, pero como sus métodos de laboreo habían quedado obsoletos, la Corona, bien asesorada, hubo de recurrir a científicos e ingenieros españoles y extranjeros para explotar adecuadamente el yacimiento de azogue. Pese al gran incendio de las labores subterráneas, ocurrido en enero de 1755, que no pudo ser apagado hasta julio de 1757, y otros percances de menor entidad, la producción de azogue de la segunda mitad del XVIII superó con creces a la del siglo y medio anterior en su conjunto ${ }^{47}$.

Tabla 1. Producción de azogue en Almadén (quintales castellanos).

\begin{tabular}{cc} 
Período & Producción \\
\hline $1600-1650$ & 184343 \\
$1650-1700$ & 108611 \\
$1700-1750$ & 270853 \\
$1750-1800$ & 671005 \\
\hline
\end{tabular}

Fuente: AHN, FC-MA, legajo 3091, caja 1

A mediados del siglo XVIII, Almadén continuaba siendo un pueblo minero, alejado de cualquier núcleo poblacional importante y con malas comunicaciones. Así lo describió Silvestre Abarca:

45 Entre 1710 y 1805 , el 76,5 \% del azogue de Almadén fue enviado a Nueva España, porcentaje que ascendió al 86 \% si se considera el período entre 1753 y 1805 (Dobado González, 2000, p. 470).

${ }^{46}$ En los treinta años transcurridos entre 1585 y 1615, Potosí había producido una media anual de unos 184000 kilogramos de plata, mientras que, al principio del siglo XVIII, la producción media había descendido a unos 46000 kilogramos al año (Bakewell, 1989, p. 42).

${ }^{47}$ Cierto es también que la actuación de los superintendentes del establecimiento minero en la segunda mitad del XVIII iba más dirigida a aumentar la producción de azogue que a disminuir el coste de producción (Dobado González, 2000, pp. 418-419). 


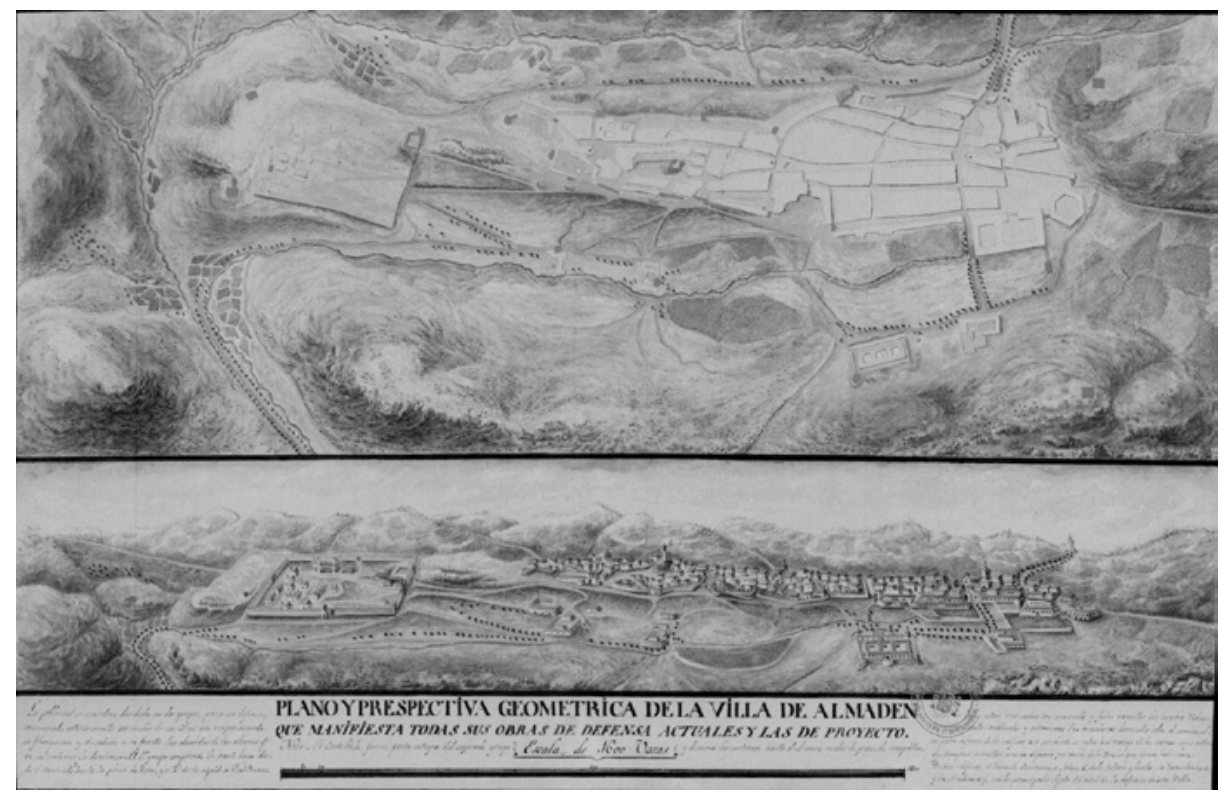

Figura 1. Plano general de Almadén (siglo XVIII), de F. Cruz, anterior a la construcción del ensanche sur. Fuente: Archivo Cartográfico del Ejército, plano 247

Está situada la Villa del Almadén sobre una Colina pelada y llena de peñascos, rodeada por todas partes de muchos Montes, su largo que corre E-O será 1350 varas y su ancho N-S de 200. La fábrica de las Casas es muy mala, hechas de piedra y barro, las más son bajas y en cada una hay tres o cuatro vecinos, de forma que están con mucha estrechez, serán 500 vecinos, pero habrá más de 4000 personas, todas se emplean en los trabajos de Minas, hasta los muchachos de 7 años que empiezan por entrar las barrenas en las minas y así se van acostumbrando. (Abarca, 1754, ff.1r-1v) ${ }^{48}$.

El rápido aumento de la población a partir de entonces obligó a la construcción de nuevas casas en la cresta del cerro alargado que forma Almadén. Como a poniente se encontraba el establecimiento minero, la villa creció hacia levante, pero estaba claro que la población necesitaba un ensanche hacia el sur, ya que no podía continuar extendiéndose de forma indefinida hacia el este. No obstante, el proyecto urbanístico del ensanche meridional se demoró hasta finales del XVIII, pero no ocurrió lo mismo con los principales edificios para el servicio de las minas ya citados con anterioridad. Todos ellos fueron construidos con materiales tradicionales de la zona, como la mampostería de cuarcita (la piedra del lugar), el ladrillo cocido, la madera de encina o madroño, y la teja árabe (Figura 1).

48 Silvestre Abarca visitó Almadén en varias ocasiones por encargo de la Corona y su rango militar era por entonces el de teniente coronel de Infantería e ingeniero en segundo. 
El expediente sobre el aumento de la población comenzó en 1777, cuando el superintendente Gaspar Soler se dirigió al ministro Joseph de Gálvez para darle parte de la conveniencia de: «la extensión de esta villa por lo apretado que se hallan estos vecinos en sus casas y no convenir por ningún modo ${ }^{49}$. Soler explicaba a Gálvez en una misiva que uno de los asuntos que más le preocupaban era:

lo reducido de la población para los vecinos con los visibles inconvenientes que de ello resultan al servicio de Dios, originados de la imposible separación de dormitorios para personas de distinto sexo y de los Padres respecto de sus hijos en lo angustiado y estrecho de las casas; resultando también perjuicio al servicio del Rey por no poderse establecer el mayor número de personas que se necesitan para el regular servicio de estas Minas; ni menos alojarse en las temporadas de Invierno la gente forastera que concurre y se hace forzoso admitir y sin la cual sería imposible ejecutar las sacas de azogue $^{50}$.

Soler explicaba más adelante en la citada carta las dificultades topográficas de Almadén, «a causa de estar situado este Pueblo sobre la Cresta o Cordillera del mismo Cerro, en cuyo centro se extrae la Piedra Mineral de Azogue de estas dos Minas ${ }^{51}$. En cambio, en la vaguada situada al sur de la colina alargada que forma Almadén había: «un suelo más llano y apacible para la extensión del Pueblo, pero se presenta el embarazo que no he podido superar de que el expresado terreno pertenece a dueños particulares que lo poseen dividido en varias piezas circundadas de paredes o pequeñas tapias para el beneficio de la labor o sementera que en ellas ejecutan sin que voluntariamente quieran adherir a la enajenación ${ }^{52}$.

Por tanto, no cabía más remedio que obligar a los dueños a vender las parcelas por el valor de tasación, pues la expropiación estaba justificada por necesidad pública. Lo más curioso del caso era que dichos terrenos habían sido públicos, «destinados en su origen a ejido para pasto del ganado del común y con el fin de reducirlos a labor para sementera se solicitaron por vecinos y se concedieron por el Ayuntamiento con muy corto o ninguno desembolso $»^{53}$.

El plan propuesto por Soler gozó de la aprobación regia, así que pocos días después Gálvez le comunicaba que: «quiere desde luego S.M. ponga en ejecución el Proyecto por medio de obligar a los Dueños a que edifiquen o vendan por el valor de la tasación sus respectivos sitios a los que quieran fabricar las casas» ${ }^{54}$. Como

\footnotetext{
${ }^{49}$ AHN, FC-MA, legajo 1718. Expediente sobre el aumento de la población.

50 Ibid., carta de Soler a Gálvez, Almadén, 17 de septiembre de 1777.

51 Ibid. Se refería Soler a la mina del Pozo o de la Hoya y a la del Castillo.

52 Ibid.

53 Ibid.

54 Ibid. Carta de Gálvez a Soler, San Idelfonso, 6 de octubre de 1777.
} 
la población crecía sin parar, José Agustín Castaño, nombrado superintendente de la mina y gobernador de Almadén en 1783, se dirigió también a José de Gálvez para proponerle la construcción de nuevas casas «en las Cercas contiguas al Cerco de la Factoría a la parte del Mediodía ${ }^{55}$. Como no podía ser menos, S.M. aprobó el proyecto y Gálvez ordenó a Castaño que uproceda a la tasación del terreno y a reconvenir a los Dueños de las Cercas a que edifiquen o en su defecto impongan el censo correspondiente los que vayan pidiendo solares $»^{56}$.

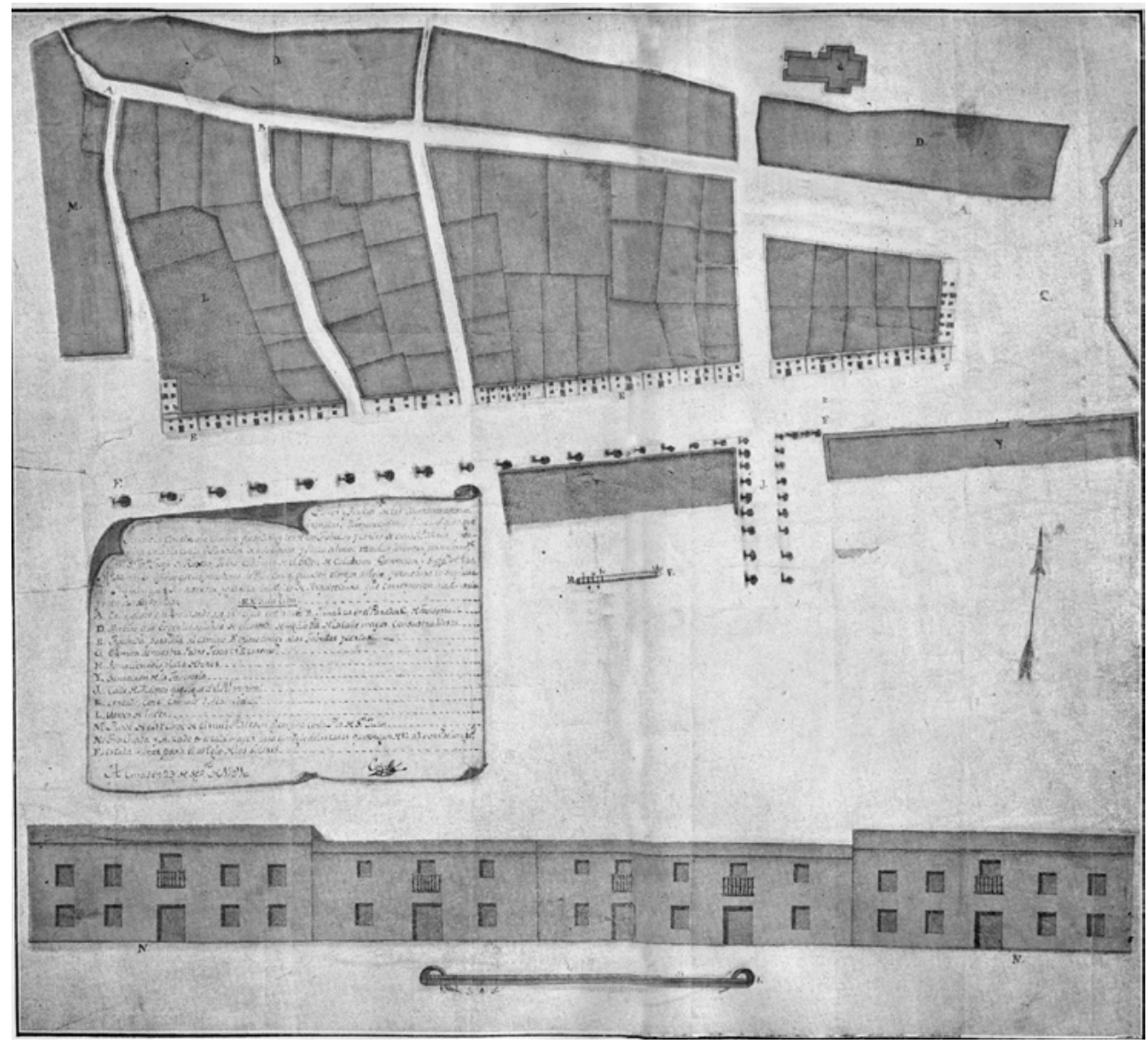

Figura 2. Plano y perfil de las nuevas casas con sus tránsitos y comunicaciones, mandado hacer por José de Rojas y Hierro ${ }^{57}$. Dibujado por Coto (1791). Fuente: Pontes, 1900

55 Ibid. Expediente sobre el proyecto de casas [...] Almadén, 19 de julio de 1785.

56 Ibid. Carta de Gálvez a Castaño, San Idelfonso, 23 de agosto de 1785.

57 Superintendente de la mina y gobernador de Almadén, sucesor de José Agustín Castaño. 
Además de las decenas de casas citadas, en la segunda mitad del siglo XVIII se construyó en Almadén un conjunto de edificios para dar diferentes servicios al establecimiento minero, ya fueran hospitalarios, carcelarios o académicos. Las fábricas arquitectónicas de los mismos pertenecen a un neoclasicismo incipiente, pero en todo caso no fueron construidos por reconocidos arquitectos sino por los maestros de obras o de arquitectura, como también se les llamaba, o por el ingeniero militar Silvestre Abarca, en el caso de la Real Cárcel de Forzados y Esclavos $^{58}$. De esta manera y con toda justicia, la villa minera de Almadén quedó unida así al conjunto de localidades en las que existen magníficos edificios creados para la industria, como la Casa de la Moneda de Segovia, la Fábrica de Porcelana de Sargadelos, en Lugo, o los arsenales militares de Cartagena, El Ferrol y la Carraca ${ }^{59}$. En Almadén, además de las propias construcciones mineras y metalúrgicas de gran valor histórico, como el conjunto del castillete metálico y sala de máquinas del pozo San Aquilino (finales del XIX), los hornos de aludeles San Eugenio y San Julián (año 1720) o la puerta monumental de Carlos IV (año 1795), hay varios edificios dispersos por la villa minera, unos civiles y otros religiosos, de los cuales se citan a continuación los cuatro más interesantes:

La Plaza de Toros es probablemente la única del mundo con forma hexagonal y fue construida así con el propósito de albergar 24 viviendas para alquilar a los forasteros que quisieran asentarse en Almadén para trabajar en sus minas de azogue. En el interior del edificio hay un coso taurino. El propósito del superintendente y gobernador Villegas quedaba claro en su decreto fundacional de 1752: «la especial utilidad de extender a la población y la de quitar a los dueños de casas el gravamen de hospedar a los forasteros que acuden a los trabajos de las minas» ${ }^{60}$. Las casas tenían dos habitaciones cada una y la plaza, además de las fiestas de toros, servía también de mercado de abastos y corral del concejo. La mayor parte del edificio se levantó entre 1752 y 1762, pero no sería hasta 1765 cuando se concluyó, con un coste total de 320000 reales de vellón (Sumozas García Pardo, 2012, p. 120).

La Plaza de Toros se levantó en lo alto del cerro de Almadén, a unos 750 metros al este del recinto minero, en un paraje conocido como «La Cruz de Hierro».

${ }^{58}$ El proyecto de la Plaza de Toros lo firmó Villegas, pero probablemente, su autor fuera Everardo Pavis, maestro de obras y arquitectura del establecimiento minero, de origen francés. Pavis tal vez fue también el autor del proyecto del Real Hospital de Mineros, mientras que el de la Academia de Minas fuera el maestro de obras Antonio del Villar. Para la biografía de este último, véase Gil Bautista, 2011.

${ }^{59}$ Carlos III decidió impulsar la política industrial iniciada por sus antecesores y durante su reinado también se crearon en Castilla-La Mancha varias fábricas reales, como la de metales en San Juan de Alcaraz, la de paños en Brihuega, la de tejidos de seda en Talavera, la de espadas en Toledo y la de pólvora en Ruidera (Lozano, 2011, p. 293).

${ }^{60}$ AHN, FC-MA, legajo 1187. Decreto del sr. Don Francisco Xavier de Villegas [...] con fecha de 1 을 de agosto de 1752 para verificar la construcción de la nueva plaza y casas. 
En cuanto a su arquitectura, el académico Bonet Correa la considera el edificio más singular de Almadén:

De planta hexagonal, tiene graderíos y balcones cubiertos en su perímetro interno en el coso; en su exterior está compuesta por viviendas de vecinos. La combinación plaza de toros-edificio de habitación no fue extraña en el siglo xvIII y primera mitad del XIX. Los casos de las plazas octogonales de Archidona, Aguilar de la Frontera, pero sobre todo de Tafalla y Valladolid, demuestran nuestra afirmación [...] esta de la ciudad de las minas sería cronológicamente la segunda plaza de toros hasta ahora conocida. (Bonet Correa, 1974, p. 86) (Figura 3).

El Real Hospital de Mineros fue edificado para curar a los operarios de los accidentes que se producían en la mina y de las enfermedades profesionales, así como del paludismo, que afectó gravemente a los habitantes de Almadén a lo largo del XVIII. En 1735 hubo una gran epidemia que provocó la muerte de muchos vecinos y en 1751 se presentó de nuevo, "se enterraron en esta Parroquia más de 330 cuerpos, entre ellos treinta forzados, y regulo según el vecindario que corresponden

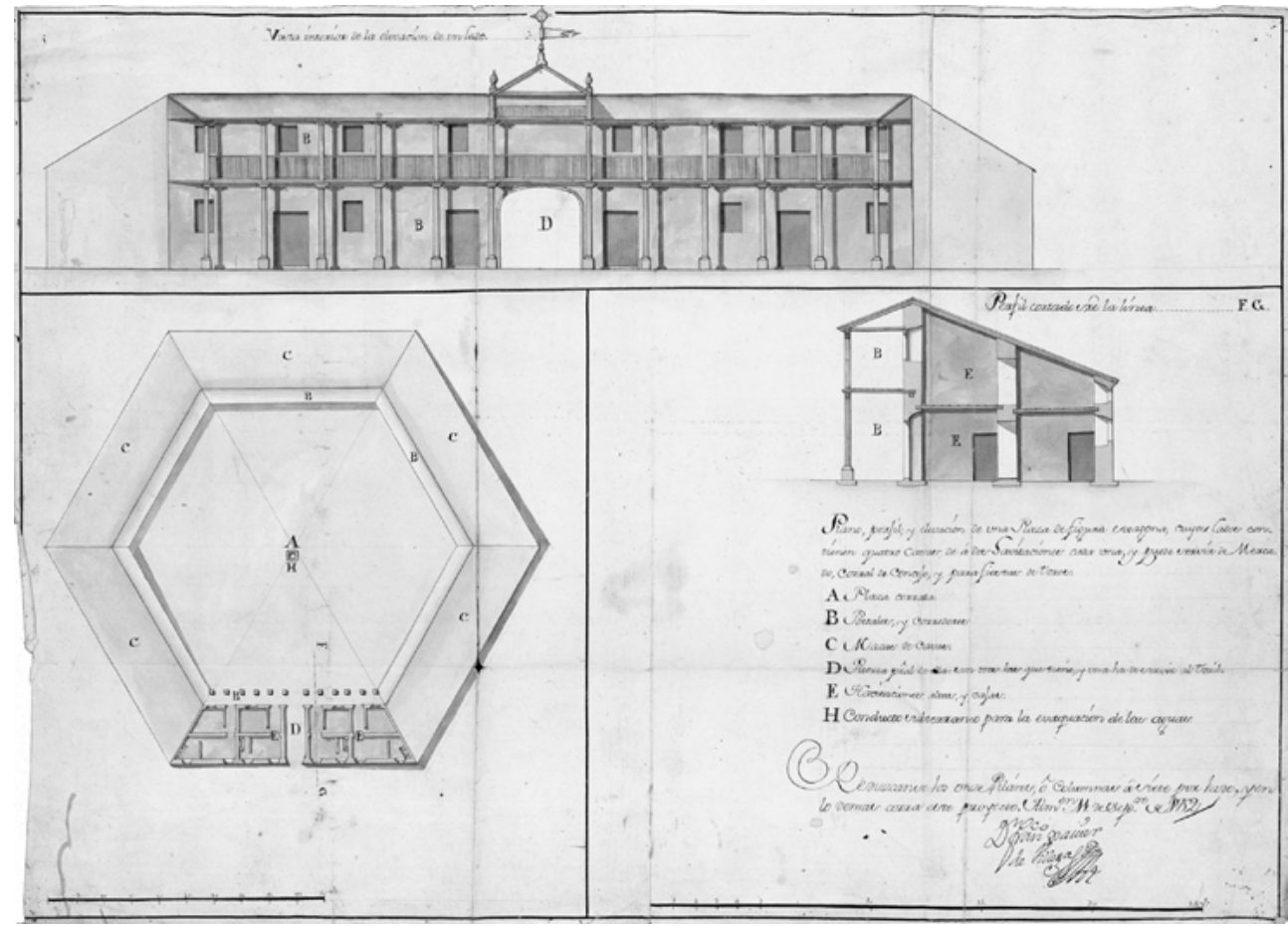

Figura 3. Plano de la Plaza de Toros de Almadén.Fuente: AHN, FC-MA, legajo 1728. Documentos gráficos y fotográficos 
a más de diez por ciento ${ }^{61}$. El superintendente Villegas temió que en 1752 iba a ocurrir lo mismo, como así sucedió. A finales de julio, estalló un nuevo brote de paludismo entre los forzados de la cárcel antigua, ascendiendo a más de 60 el número de afectados (Menéndez Navarro, 1996, p. 225). En la antigua cárcel se hacinaban casi 200 forzados en condiciones higiénicas deplorables y su cercanía al núcleo urbano favorecía el contagio al resto de la población, así que Villegas comunicó a sus superiores que:

las enfermedades de la cárcel son muchas, pues pasan de 60 los forzados que se hallan en cama, de forma que ya ocupan la iglesia por falta de enfermería y es una indecencia que se celebre en ella. Si trasciende al pueblo, como es regular será el clamor igual al del año pasado y el del 35, porque a los accidentes de la Mina se añade la falta de Hospital y dotación, y ser los habitantes correspondientes a dos poblaciones como la actual ${ }^{62}$.

Cierto es que en la cárcel había una pequeña enfermería para forzados, atendida por un médico y un cirujano, mientras que los vecinos de Almadén eran cuidados en el Hospital de la Caridad, pero ambos resultaban claramente insuficientes para tanto enfermo, por lo que por una Real Orden de 28 de agosto de 1752 se fundó el Real Hospital de Mineros de San Rafael.

Los fondos para la construcción y funcionamiento del hospital provinieron de la Real Hacienda, los ingresos del alquiler de los inmuebles propiedad del establecimiento minero, incluyendo las viviendas de la Plaza de Toros cuando estuvieron terminadas, así como de los beneficios de las corridas de toros. Además, se dedicaron a la construcción del hospital las multas que se ponían a los trabajadores por descuidos o mal comportamiento y el beneficio de la venta de víveres a los operarios de Almadenejos, otra mina de azogue situada a unos doce kilómetros a levante de Almadén. Al igual que la Plaza de Toros, la construcción del Real Hospital de Mineros duró una docena de años, así que tal y como se ve en los dos escudos de la fachada principal, cuando comenzaron las obras en 1755 reinaba en España Fernando VI y el superintendente de la mina era Villegas, y cuando terminaron en 1773, el rey era Carlos III y el superintendente era Gijón y Pacheco. El gasto total de construcción ascendió a casi 366000 reales $^{63}$. A partir de 1774, la asistencia sanitaria de los operarios de las minas y de sus familias mejoró considerablemente,

${ }^{61}$ AHN, FC-MA, legajo 772. Carta de Villegas a D. José De Carvajal y Lancaster, superintendente general de Azogues.

62 AHN, FC-MA, legajo 772. Comunicación del superintendente Villegas al superintendente general de Azogues, Almadén, 1 de agosto de 1752.

63 Ibid., legajo 1187. 
convirtiéndose este Real Hospital en una de las mejores instituciones asistenciales del siglo XVIII, dedicada a conservar la salud de los trabajadores.

El hospital entró en funcionamiento en 1774 y a medida que surgieron nuevas necesidades asistenciales el edificio se fue ampliando con nuevos espacios y construcciones, como un gran patio con pozo y lavadero, la casa del capellán, la capilla y otros, siempre con arreglo a criterios funcionales y de economía constructiva. El edificio tiene forma de $L$ y está volcado hacia el gran patio interior. Construido con muros de mampostería de un metro de espesor, su cubierta es de teja cerámica curva. La fachada principal está compuesta por la portada y por tres cuerpos de dos piezas situadas a ambos lados de ella. En el umbral de la puerta se sitúan las escaleras de acceso y desde el punto de vista arquitectónico,

lo que tiene mayor interés es su fachada con una portada central en la que domina una sobria ordenación rematada por una espadaña. Coronando la totalidad, en un nicho, hay un arcángel San Rafael. De proporciones muy poco esbeltas, este santo ángel, patrón de los médicos, de iconografía muy rococó, podría muy bien por su aire encontrarse en cualquier edificio de una población hispanoamericana. (Bonet Correa, 1974, p. 86).

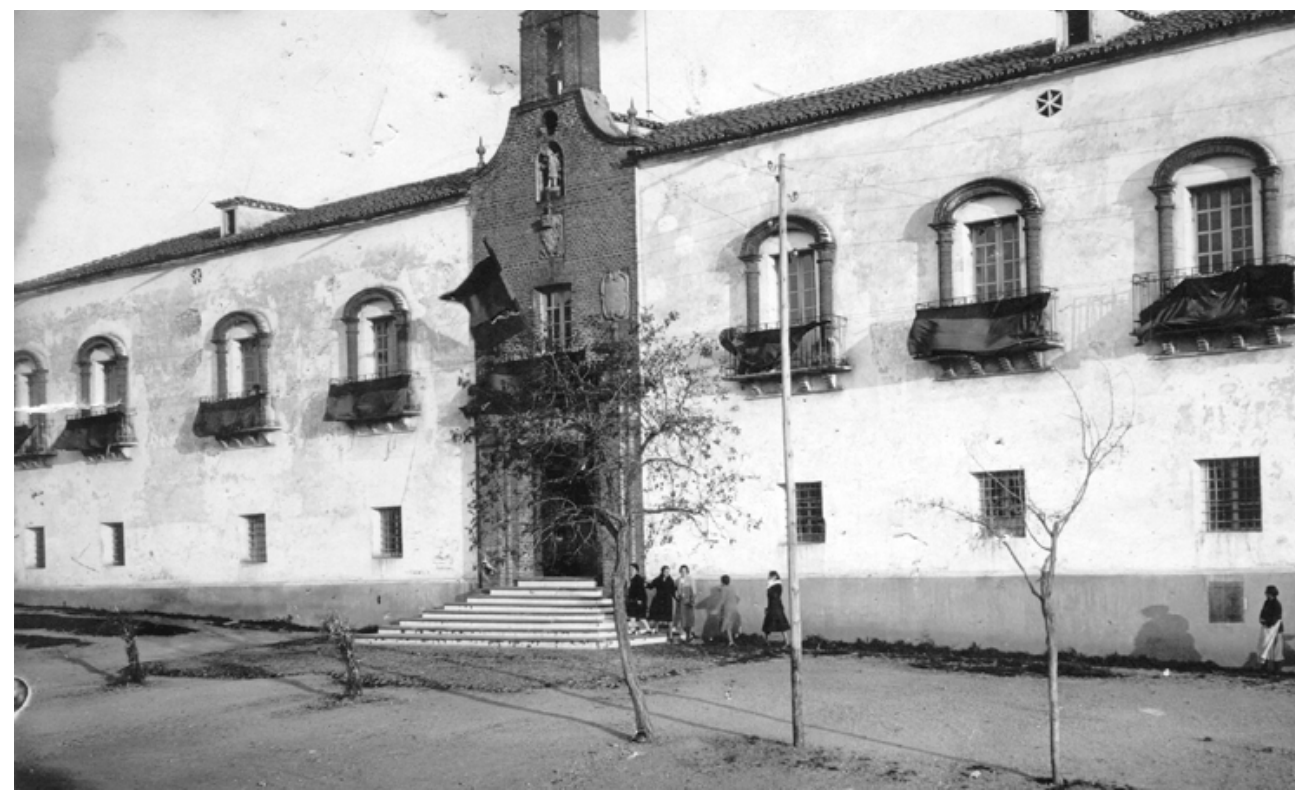

Fotografía 3. Fachada principal de Real Hospital de Mineros. Fuente: AHN, FC-MA, legajo 1728. Documentos gráficos y fotográficos 
En los párrafos anteriores quedan desentrañadas las claves del proyecto ilustrado formado por el conjunto de plaza de toros y hospital de mineros. Sus artífices fueron tres personajes que coincidieron temporalmente en la década de 1750 y que estaban unidos por la cadena de mando: Villegas, superintendente de la mina y gobernador de Almadén; Carvajal, superintendente general de Azogues; y Ensenada, ministro de Indias. La misiva ya citada de Villegas a Carvajal y otras similares enviadas al mismo Carvajal y a Ensenada dejan al descubierto el plan de mejora de las condiciones sociolaborales de los mineros del azogue:

He premeditado que todo el caudal de algunas imágenes y obras pías de que la villa es vicepatrona, se conviertan en hacer casas y que estas formen una plaza, por la falta que tiene este pueblo de ella. El caudal de multas que llevo aplicadas al hospital ha de servir al mismo fin. Por este motivo se logrará la extensión en la población; y hecha la plaza, convendrá permitir cada año seis u ocho fiestas de toros, y su producto destinarlo a la construcción de un hospital, en que no tenga qué hacer el Ordinario, pues sin él, sucederá a los forasteros que acuden a estos trabajos lo que a los mitayos ${ }^{64}$.

Así pues, el Ordinario, es decir, el resto de la población no tendría acceso al hospital sino solo los operarios fijos y temporales de la mina para que no les ocurriera lo mismo que a los mitayos de Huancavelica, los cuales padecieron mucho con los accidentes y las enfermedades propias de su oficio.

También sería al comienzo de la década de 1750 cuando el superintendente $\mathrm{Vi}$ llegas propuso a la superioridad la construcción de una nueva cárcel para los forzados, pues el paludismo hacía estragos entre ellos al comienzo del estío. Además, la enfermedad se contagiaba a los operarios de la mina y a los vecinos de Almadén en general. Por ello, el lugar elegido para su edificación se encontraba situado a unos 300 metros de las casas de vecindad, al igual que ocurriría con el Real Hospital de Mineros, también construido en el extrarradio de Almadén por el mismo motivo ${ }^{65}$. En 1751 se amontonaban en la cárcel vieja 267 forzados, los cuales habían protagonizado varias fugas y sublevaciones, en ocasiones multitudinarias:

De hallarse sin más prisiones que las referidas, bien comidos y solos en las Minas se han originado dos sublevaciones y de ellas dos fugas quasi generales y como están persuadidos [de que] no se les puede imponer la pena de muerte por la fuga, aunque sea con quebrantamiento [de cadenas] y se les ha tolerado la sublevación que hicieron en la cárcel el año de 49 [1749], negándose a recibir el sacramento de la Penitencia y otros excesos que han tenido con los sobrestantes, acaban de ejecutar el extraordinario de haberlos atado dentro de la Mina con los demás libres que estaban por celadores de

\footnotetext{
${ }^{64}$ AHN, FC-MA, legajo 772, carta de Villegas a Carvajal.

${ }^{65}$ La nueva cárcel y el Real Hospital distaban entre sí unos 200 metros.
} 
sus operaciones y el de haberse huido cuarenta y siete de ellos, dejando quebrantadas tres puertas y rejas de hierro y abierta otra de red $^{66}$.

Para el proyecto de la nueva cárcel, Villegas trajo a Almadén al maestro de arquitectura Juan Alejandro Núñez, vecino de Almagro, a quien sin duda conocía ${ }^{67}$. El proyecto constructivo, difícil de presupuestar porque algunos materiales, como la cal y el yeso, habían de traerse de lejos, ascendió a unos 50000 pesos (400 000 reales) (Hernández Sobrino, 2010, p. 185).

La construcción del edificio comenzó en 1751 y terminó en 1754, si bien los forzados permanecieron en la antigua cárcel hasta 1756. Su construcción se encargó al ingeniero militar Silvestre Abarca, quien por entonces se hallaba destinado en Almadén y a quien la Corona le había encargado obras similares, como el campamento militar de Aranjuez:

Se resolvió también que para que los forzados fuesen útiles al Real Servicio en aquellos trabajos, se debía hacer una Cárzel [sic] para 600 con toda la custodia correspondiente, a fin de poder obligar a que trabajasen lo que deben y que se arranchasen ${ }^{68}$, disminuyéndoles la ración y coordinando de otro modo todo aquello que estaba muy mal dispuesto y le costaba al Rey mucho con poca utilidad. (Abarca, 1754 , f. 5v).

Como el recorrido desde la nueva cárcel hasta la puerta del socavón de entrada a la mina era de más de 400 metros, se decidió construir una galería subterránea de comunicación entre la cárcel y la mina para evitar fugas: «El socavón o Galería que se abre para la comunicación de los forzados desde la nueva Cárcel a las Minas lo han hecho los peones de la obra de la dicha Cárcel por la mitad menos que los naturales sin emplear madera alguna, no obstante, de ser en pizarra» (Ibid.: fol.24v). Lamentablemente, Bonet Correa no pudo describir el edificio por haber sido derruido en 1969, cinco años antes de su visita a Almadén, pero se han conservado diversos planos y fotografías además de una descripción exhaustiva, fechada en 1822, que se guarda en el Archivo Municipal de Almadén ${ }^{69}$.

${ }^{66}$ AHN, FC-MA, legajo 63, caja 2, Providencia de Villegas [...], 21 de julio de 1751.

${ }^{67}$ El superintendente Villegas era oriundo de Almagro y caballero de la Orden de Calatrava. Durante su estancia en Almadén (1749-1757), Villegas volvió algunos veranos a Almagro para recuperar su salud.

${ }^{68}$ Se refiere a juntarse en grupos para cocinar y comer juntos, lo que hacían en el patio central porticado de la nueva cárcel.

${ }^{69}$ AMA. Descripción de la Real Cárcel de Forzados realizada por una comisión delegada del Ayuntamiento de Almadén, año 1822. 


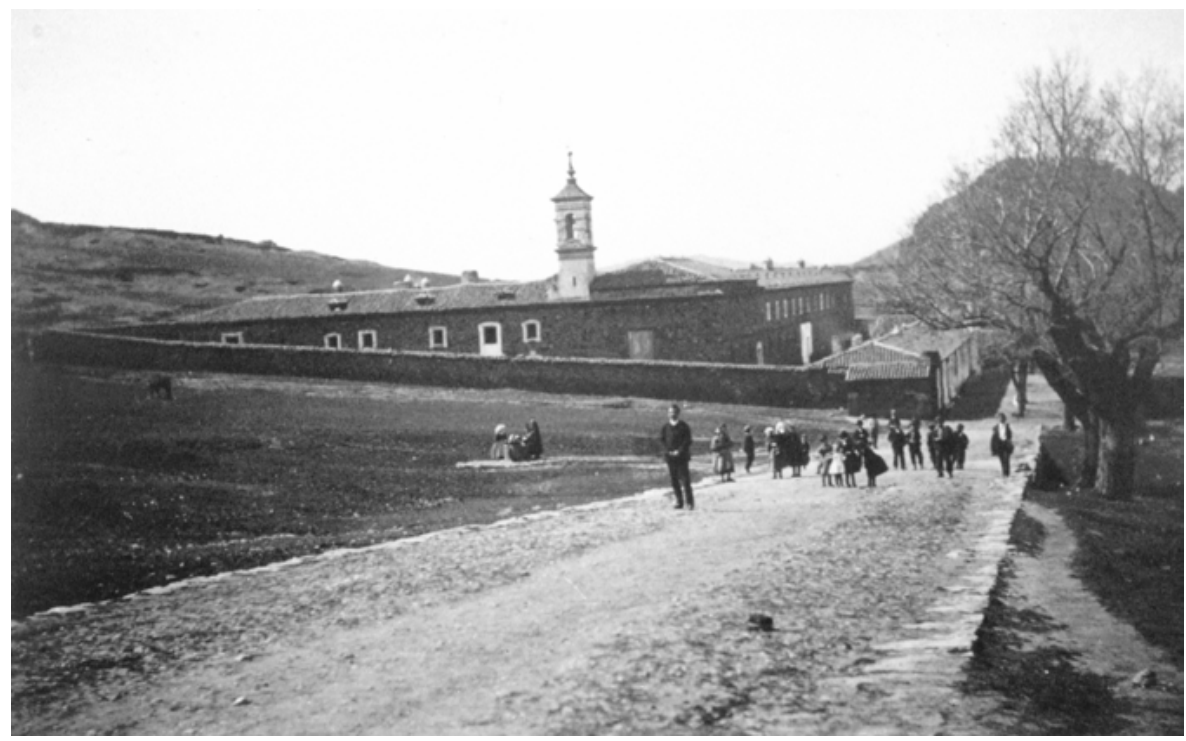

Fotografía 4. Real Cárcel de Forzados. Fuente: AHN, FC-MA, legajo 1728. Documentos gráficos y fotográficos

Otra de las soluciones adoptadas por Ensenada y su sucesor Arriaga, ambos ministros de Indias, para multiplicar la producción de azogue de Almadén en la segunda mitad del XVIII fue la contratación de ingenieros y maestros de mina alemanes, quienes estaban a la vanguardia de la minería en Europa $^{70}$. El encargado de su selección fue el naturalista irlandés Guillermo Bowles, a quien conoció Antonio de Ulloa en París en 1752, que le propuso ponerse a las órdenes de la Corona de España. Bowles aceptó la proposición y permaneció en nuestro país hasta su muerte, ocurrida en 1780 , recorriéndolo sin descanso mientras sus fuerzas se lo permitieron ${ }^{71}$. El primer lugar que visitó Bowles en España fue Almadén, año 1752, donde comprobó que:

Los Mineros Españoles de Almadén son atrevidos y tienen robustez, maña y penetración cuanta es menester, de suerte que con el tiempo serán excelentes Mineros, pues no le falta otra cosa que la verdadera ciencia de las minas, la cual consiste en el conocimiento de las vetas y dirección de las peñas, que en el Arte del Minero viene a ser lo que la experiencia en el uso de vida ${ }^{72}$.

70 En total, alrededor de medio centenar de técnicos y maestros mineros alemanes llegaron a Almadén en la treintena de años que transcurren entre 1754 y 1783 (Matilla Tascón, 1987, pp. 270-282).

${ }^{71}$ Su obra quedó plasmada en su libro Introducción a la Historia Natural y a la Geografía Física de España, si bien él mismo reconoció en el discurso preliminar que: «no pretendo escribir la milésima parte de lo que hay que decir de la Historia Natural y Minas de España, son un ensayo de estas cosas» (Bowles, 1775).

72 Ibid:15. 
Bowles se desplazó en 1754 a los montes del Harz, en Alemania, donde estaban situadas las famosas minas de Goslar y Clausthal, y donde comenzó a contratar ingenieros y maestros de mina. El primer ingeniero alemán en llegar a Almadén en 1754 fue Henning Karl Koehler, quien falleció prematuramente en $1757^{73}$. Su sucesor debía haber sido Enrique Cristóbal Storr, quien había llegado a Almadén en 1756, pero todavía veinte años después no le habían concedido el título de director. Por fin, una Real Orden de 14 de julio de 1777 le otorgó el ansiado: «título de Director o Delineador de las expresadas Minas [...] y de enseñar a los Jóvenes Matemáticos y a los que en virtud de Real orden se destinaren a esta villa, las relacionadas ciencias de Geometría Subterránea o Mineralogía con el debido cuidado y aplicación $\aleph^{74}$. El nombramiento de Storr llevaba pues asociado el de profesor de geometría subterránea o mineralogía de la Academia de Minas de Almadén, cuya fundación coincidía precisamente con la fecha de su nombramiento ${ }^{75}$.

Al principio, la Academia se alojó en edificios alquilados a tal fin, pero una Real Orden de 8 de junio de 1781 dotó de sede propia a la institución académica. En un primer momento se contempló la idea de construir dos edificios, uno propiamente para la Academia y otro como residencia de alumnos, pues estos provenían de diversos lugares de España, como Madrid o Barcelona (Sumozas García Pardo, 2012, p. 110). Finalmente se decidió hacer un edificio único para las dos funciones y se encargó el proyecto y su construcción al maestro de obras Antonio del Villar (Gil Bautista, 2013, p. 82). El edificio se empezó a cimentar en 1782 y se ocupó en 1785 , cuando ya Storr se había jubilado y el nuevo director de la mina y su academia era otro ingeniero alemán, Johann Martin Hoppensak. A diferencia de la Plaza de Toros, del Real Hospital y de la Real Cárcel, la Academia de Minas se construyó en la calle Mayor, a escasos 150 metros de los pozos de la mina. Para Bonet Correa, la Academia de Minas es:

el edificio más noble de la ciudad [...] De sólida fábrica, construido sobre un solar pendiente de forma que su parte posterior tiene varios pisos con bodegas y plantas subterráneas, a la calle tiene una fachada de dos plantas. Es esta de orden clásico con aparejos en rústica, lo que es muy propio de una arquitectura de ingeniero. Construcción de gran prestancia y dignidad, muy significativa del prospecto con que se quería dar categoría a una profesión entonces muy en boga y considerada académicamente. (Bonet Correa, 1974, pp. 86-87).

${ }^{73}$ No se conoce la causa exacta de la muerte de Koehler, ocurrida el 10 de julio de 1757, pero probablemente fue por paludismo, enfermedad que por aquellos años hacía estragos en Almadén. Libro cuarto de defunciones de la parroquia de Santa María de la Estrella, f. 17.

74 AHN, FC-MA, legajo 3519, caja 1.

75 La Academia de Almadén se estableció a imagen y semejanza de otras que se habían inaugurado años antes en Europa, entre ellas la de Clausthal, año 1775. 


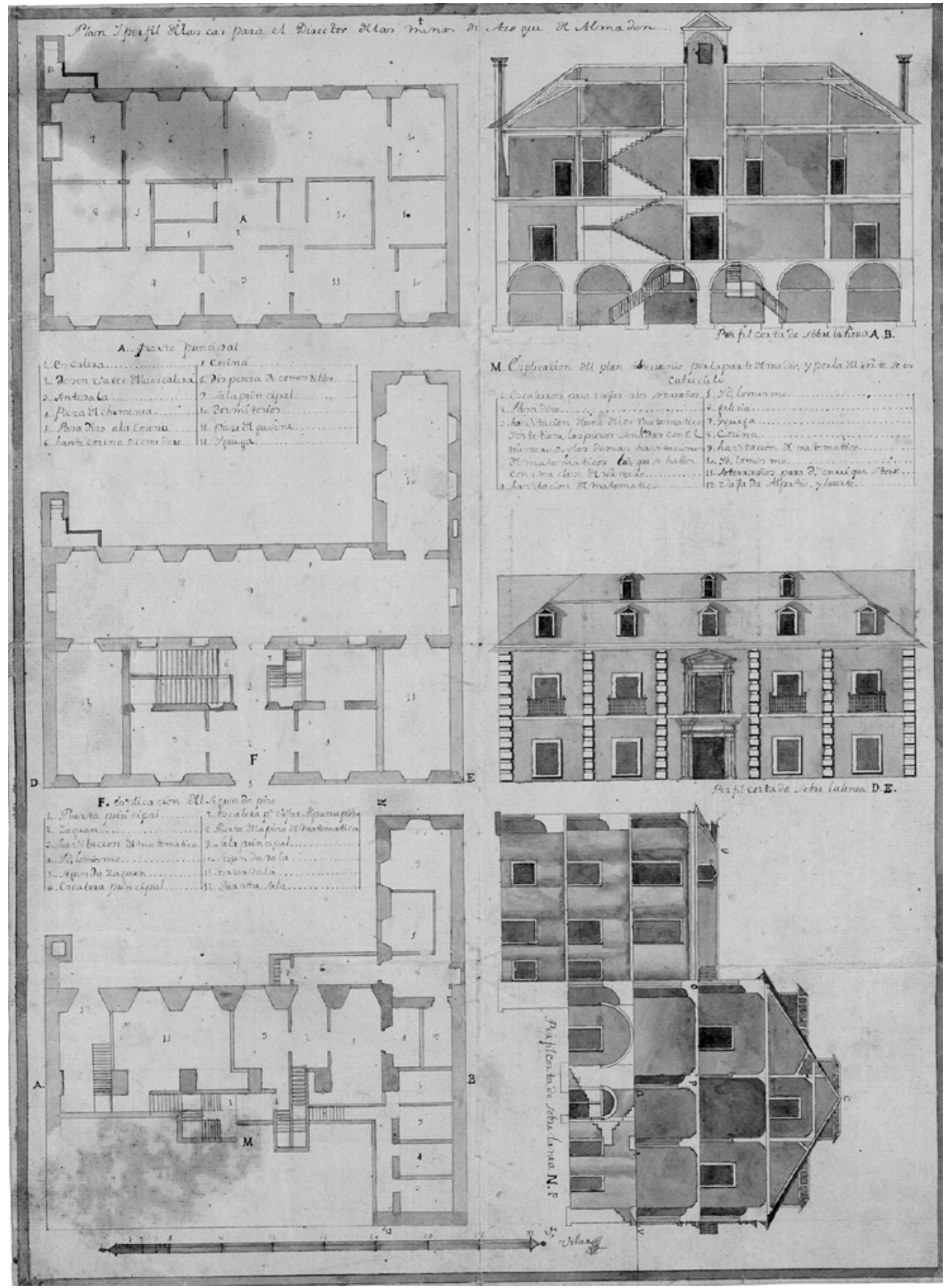

Figura 4. Plano y perfil de la Academia de Minas. Fuente: AHN, FC-MA, legajo 1728. Documentos gráficos y fotográficos 


\section{CONCLUSIONES}

Almadén fue, sin duda, la mina más importante de la España metropolitana en la Edad Moderna, pues sin su azogue era imposible explotar los yacimientos de plata novohispanos. Sin embargo, ni la administración española ni la de los Fugger (1525-1645) contribuyeron a que además de ser una gran mina fuera un buen lugar para vivir. Todas las descripciones de los visitantes entre mediados del XVI y mediados del XVIII aluden a un pueblo construido sobre una mina, de manera que los operarios solo habían de desplazarse unos pocos centenares de metros para llegar a los socavones por los que accedían a sus puestos de trabajo; los centenares de casas que formaban la población estaban hechas casi todas de piedra y barro, y se extendían de manera irregular por lo alto de la colina alargada que forma Almadén; la mayor parte de las calles estaban sin empedrar y no tenían aceras, lo que las convertía en polvorientas en verano y barrizales en invierno.

En cambio, en la segunda mitad del XVIII Almadén experimentó un cambio radical, tanto en su urbanismo como en su arquitectura. Decenas de nuevas casas espaciosas y cómodas se construyeron en el ensanche de la villa a lo largo de la vaguada meridional del cerro de Almadén, lo que permitió por fin alojar de manera digna a los numerosos forasteros que venían por entonces a trabajar en el establecimiento minero. Las principales calles de la localidad se empedraron y se hicieron las aceras correspondientes, y las de nueva construcción fueron de trazado recto y más anchas. Por otra parte, se construyeron varios edificios emblemáticos para dar mejores servicios al establecimiento minero, entre los que destacaban la Plaza de Toros, el Real Hospital de Mineros, la Real Cárcel de Forzados y Esclavos, y la Academia de Minas. De esta manera, y solo en unas pocas décadas, Almadén se había transformado de un villazgo pequeño y de forma irregular, asentado sobre una mina subterránea, en una amplia villa minera con el doble de población.

Lamentablemente, una parte de este patrimonio arquitectónico ha sido destruido, como la casa de la Superintendencia, de la que solo queda en pie la portada, o la Real Cárcel de Forzados y Esclavos, en donde solo ha sido posible rehabilitar las celdas de castigo y gracias a que estaban construidas bajo el nivel del suelo. En muchas ciudades, el patrimonio arquitectónico industrial ha sido derribado por la voracidad inmobiliaria, mientras que en Almadén la causa ha sido la ignorancia o la desidia. Por fortuna, en la sociedad actual hay un fuerte sentimiento conservacionista del patrimonio industrial en general, que ha pasado así del olvido a la memoria colectiva. El patrimonio minero, como un tipo más del patrimonio industrial, se ha convertido ya en un recurso del territorio y en un componente más del paisaje, $y$ explica el modo en que el hombre ha explotado la riqueza mineral y transformado el medio natural. En Almadén, la cultura de la minería del azogue no solo se ha conservado y restaurado la mina y la población en los dos primeros decenios del siglo XXI, sino que se ha convertido en un atractivo turístico de primer orden, de manera que 
sus visitantes actuales comprenden las técnicas y los modos de vida que la actividad minera encerraba en siglos pasados (Cañizares Ruiz, 2008, pp. 9-31). Las viviendas y los edificios históricos que se encuentran dispersos por Almadén incrementan el interés de la visita, ya que permiten conocer las condiciones de vida de los mineros.

\section{REFERENCIAS BIBLIOGRÁFICAS}

\subsection{Fuentes manuscritas}

Abarca, S. (1754). Proyecto General para las Minas de Azogue que se hallan en la Villa del Almadén [...]. Madrid: Instituto de Historia y Cultura Militar (IHCM).

Archivo Cartográfico del Ejército, plano 247.

Archivo General de Indias (AGI), MÉXICO, 22, N. 19.

Archivo Histórico Nacional (AHN), Fondos Contemporáneos-Minas Almadén (FCMA), legajos 621, 772, 1187, 1307, 1556, 1718, 1728, 3091 caja1 y 3519.

Archivo Municipal de Almadén (AMA), legajo 32, Libro de Acuerdos, 11. Descripción de la cárcel de forzados por la Comisión Delegada, año 1822.

Parés y Franqués, J. (1785). Descripción histórico-phísico-médico-mineralógicomercurial de las Reales Minas de Azogue de la Villa de Almadén, ms. 488. Madrid: Archivo Central y Biblioteca del Ministerio de Economía y Hacienda.

Parés y Franqués, J. (1788). Catástrofe morboso (sic) de las minas mercuriales de la villa de Almadén del Azogue, ms. 489. Madrid: Archivo Central y Biblioteca del Ministerio de Economía y Hacienda.

Real Academia de la Historia (1575). Relaciones o descripciones geográficas de los pueblos de España mandadas hacer por Felipe II. T. III, J.I.14-776 ff. y 94 Relaciones. Almadén 194-199v.

\subsection{Fuentes impresas}

Aguilar Civera, I. (2004). El patrimonio arquitectónico industrial valenciano. Algunos ejemplos, Saitabi, 54, pp. 155-192. https://ojs.uv.es/index.php/saitabi/article/ view/6179/5936 
Álvarez Nogal, C. (1997). El crédito de la monarquía hispánica en el reinado de Felipe IV. Valladolid: Junta de Castilla y León.

Bakewell, P. (1989). Mineros de la Montaña Roja. Madrid: Alianza Editorial.

Benito del Pozo, P. (2009), et al. Recuperar y rehabilitar el patrimonio industrial urbano. Entre el desamparo institucional y la voracidad urbanística. Ciudades, 12, pp. 197-219. https://doi.org/10.24197/ciudades.12.2009.197-219

Bonet Correa, A. (1974). Urbanismo y arquitectura en Almadén. Goya, Revista de Arte, no 122 , pp. 83-88.

Bowles, G. (1775). Introducción a la historia natural y a la geografía física de España. Madrid: Imprenta de D. Francisco Manuel de Mena.

Cañizares Ruiz, M. C. (2008). El atractivo turístico de una de las minas de mercurio más importantes del mundo: El Parque Minero de Almadén (Ciudad Real). Cuadernos de Turismo, 21, pp. 9-31. https://revistas.um.es/turismo/article/ view/24971/24261

Comisión Europea (1999). Estrategia Territorial Europea. Luxemburgo.

Dobado González, R. (2000). Las técnicas productivas en Almadén, 1759-1808. En J. Sánchez Gómez y G. Mira Delli-Zotti (comps.), Hombres, Técnica, Plata. Minería y sociedad en Europa y América, siglos XVI-XIX. Sevilla: Aconcagua Libros.

Gil Bautista, R. (2009). Medicina y minería en el Almadén del siglo XVIII. Joseph Parés y Franqués (Mataró, 1720 - Almadén, 1798). Revista de Historia Moderna, 27, pp. 333-362. https://doi.org/10.14198/RHM2009.27.14

Gil Bautista, R. (2011). Técnica, ciencia y fomento en Almadén y sus reales minas de azogue en el siglo XVIII: Antonio del Villar, maestro mayor de obras (17341806). Revista de Historia Moderna, 29, pp. 1-20. https://doi.org/10.14198/ RHM2011.29.02

Gil Bautista, R. (2013). Almadén del Azogue. Una villa minera del siglo XVIII. Puertollano: Ediciones Puertollano.

Gil Bautista, R. (2015). Las minas de Almadén en la edad Moderna. Alicante: Universidad de Alicante. 
Hernández Sobrino, A. (2010). Los esclavos del rey. Los forzados de Su Majestad en las minas de Almadén, 1550-1800. Ciudad Real: Fundación Almadén.

Hernández Sobrino, A., et al. (2017). Las Cuevas, una mina romana de bermellón en Almadén. En Actas del XVII Congreso Internacional sobre Patrimonio Geológico y Minero. El patrimonio geológico y minero, identidad y motor de desarrollo. Almadén: Escuela de Ingeniería Minera e Industrial.

Larruga, E. (1792). Memorias políticas y económicas sobre los frutos, fábricas y minas de España. Tomo XVII. Madrid: Imprenta de Don Antonio Espinosa.

Lozano Bartolozzi, M.M. (2011). Historia del urbanismo en España, II. Siglos XVI, XVII y XVIII. Madrid: Cátedra.

Matilla Tascón, A. (1958). Historia de las Minas de Almadén. Vol. I: Desde la época romana hasta el año 1645. Madrid: Consejo de Administración de Minas de Almadén y Arrayanes.

Matilla Tascón, A. (1987). Historia de las Minas de Almadén. Vol. Il. Desde 1646 a 1799. Madrid: Minas de Almadén y Arrayanes, S.A. e Instituto de Estudios Fiscales.

Menéndez Navarro, A. (1996). Un mundo sin sol. La salud de los trabajadores de las minas de Almadén, 1750-1900. Granada: Universidad de Granada y Universidad de Castilla-La Mancha.

Pardo Abad, C. J. (2016). The post-industrial landscapes of Riotinto and Almadén, Spain: scenic value, heritage and sustainable tourism. Journal of Heritage Tourism. https://doi.org/10.1080/1743873X.2016.1187149

Pérez del Perceval Verde, M. A. y López-Morell, M. A. (2006). Introducción. Una visión general del sector minero en la historia contemporánea española. En Minería y desarrollo económico en España. Madrid: Editorial Síntesis.

Plan Nacional de Patrimonio Industrial. (2016). https://oibc.oei.es/uploads/ attachments/172/patrimonio_industrial.pdf

Pontes y Fernández, J.M. (1900). Historia de la antigua ciudad de Sisapon, hoy Almadén del Azogue. Madrid: Imprenta y Fotograbado de Enrique Rojas 
Sánchez Gómez, J. (1989). De minería, Metalúrgica y Comercio de Metales. Salamanca: Universidad de Salamanca.

Silvestre Madrid, M. y Almansa Rodríguez, E. (2019). Almadén en la España del siglo XVII. Crisis de producción de azogue y soluciones propuestas, Vínculos de historia, 8 (2019), pp. 337-353. https://doi.org/10.18239/ vdh_2019.08.17

Sumozas García-Pardo, R. (2007). Arquitectura industrial en Almadén: antecedentes, génesis y repercusión del modelo en la minería americana. Cuenca: Universidad de Sevilla y Universidad de Castilla-La Mancha.

Sumozas García-Pardo, R. (2012). Patrimonio monumental y minero de Almadén. Ciudad Real: Diputación de Ciudad Real.

Trujillo Valderas, J. J. (2016). Minas de San Quintín (1814-1934). Ciudad Real: Biblioteca de Autores Manchegos. 